\title{
Monetary and Macroprudential Policies under Fixed and Variable Interest Rates
}

\author{
Margarita Rubio* \\ University of Nottingham
}

September 2016

\begin{abstract}
In this paper, I analyze the ability of monetary policy to stabilize both the macroeconomy and financial markets under two different scenarios: fixed and variable-rate mortgages. I develop and solve a New Keynesian dynamic stochastic general equilibrium model (DSGE) that features a housing market and a group of constrained individuals who need housing collateral to obtain loans. A given share of constrained households borrows at a variable rate, while the rest borrow at a fixed rate. I consider two alternative ways of introducing a macroprudential approach to enhancing financial stability: one in which monetary policy, using the interest rate as an instrument, responds to credit growth; and a second one in which the macroprudential instrument is instead the loan-to-value ratio (LTV). The results show that when rates are variable, a countercyclical LTV rule performs better in stabilizing financial markets than monetary policy. However, when rates are fixed, even though monetary policy is less effective in stabilizing the macroeconomy, it does a good job in promoting financial stability.
\end{abstract}

Keywords: fixed/variable-rate mortgages, monetary policy, macroprudential policy, LTV, housing market, collateral constraint

JEL Codes: E32, E44, E52

\footnotetext{
${ }^{*}$ University of Nottingham, Sir Clive Granger Building, Nottingham. E-mail: margarita.rubio@nottingham.ac.uk. The author would like to thank Matteo Iacoviello, Fabio Ghironi and Peter Ireland for their help in the development of the modeling framework. I would also like to acknowledge comments by conference participants at the MMF 2015, the Midwest Macro Meetings 2015 and the SAEe 2015, as well as an anonymous referee. Special thanks to José A. Carrasco-Gallego for his very useful comments and support. Part of this project was undertaken while the author was visiting the National Bank of Poland, for which she acknowledges their hospitality. All errors are mine.
} 
"The explicit incorporation of macroprudential considerations in the nation's framework for financial oversight represents a major innovation in our thinking about financial regulation [...] This new direction is constructive and necessary, I believe, but it also poses considerable conceptual and operational challenges in its implementation." Ben Bernanke, May 5, 2011.

\section{Introduction}

In recent years, especially during the period of the Great Moderation, monetary policy was seen as a very powerful tool for stabilizing the economy. However, in the aftermath of the crisis, new experiences have revealed that this statement is not true for all cases nor in all circumstances. First of all, the effectiveness of monetary policy may depend on structural factors in the economy. In particular, there may be institutional features, especially in housing markets, that are country specific and that may affect the optimal conduct of policies. One source of heterogeneity, which can be crucial, is the structure of mortgage contracts. Mortgage contracts in an economy can involve either a fixed or variable rate, and the proportion of each type of mortgage varies from country to country. The link between the policy rate and fixed rates is weaker, because the latter are more connected to longer-term rates, and thus, in this case, monetary policy is less effective. ${ }^{1}$ On the other hand, with the crisis, policy and academic discussions have focused on how to ensure a more stable financial system: a macroprudential approach to prevent situations in which problems in the financial sector are transmitted to the real sectors of the economy and vice versa. It is debatable whether monetary policy alone can achieve this goal; it may need the help of other tools that help avoid excessive credit growth. The following question remains. Does the mortgage structure of the economy affect the ability of monetary policy to enhance financial stability?

In this paper, I try to shed some light on this issue. I analyze the ability of monetary policy to stabilize financial markets under two different scenarios: when the prevalent mortgage rate in the economy is variable and when it is fixed. Recent literature shows that the effectiveness of monetary policy in stabilizing the macroeconomy is reduced when rates are fixed. Nevertheless, the literature is silent about whether this feature has an impact on the potential of monetary policy to promote financial stability.

There is evidence of different cross-country mortgage contracts. While fixed-rate mortgages predom-

\footnotetext{
${ }^{1}$ See Rubio (2011) or Brzoza-Brzezina (2014) for theoretical models that show that fixed-rate contracts imply less effective monetary policy.
} 
inate in the US, the majority of consumers borrow at a variable rate in Canada and Australia. Within European countries, we have striking differences such that the vast majority of consumers in the United Kingdom and Spain have variable-rate mortgages, as opposed to Germany and France where most mortgage rates are fixed (see Table A1 in the Appendix). Rubio (2011) and Calza et al. (2013) show that the structure of mortgage contracts has important implications for the transmission of monetary policy in the sense that policy rate changes are less effective when the mortgage rate is fixed. However, these papers do not touch upon the issue of whether having fixed- or variable-rate mortgages may also affect financial stability and the optimal design of macroprudential policies.

In this paper, I build a new Keynesian dynamic stochastic general equilibrium model with housing, collateral constraints, and fixed- and variable-rate mortgages to study how the mortgage structure in an economy affects the optimal design of both monetary and macroprudential policies. In the model, there are three types of consumers: savers, variable-rate borrowers and fixed-rate borrowers. Borrowers need collateral in order to access credit markets, which are more or less tight depending on the loan-to-value ratio (LTV). Monetary policy is conducted by the central bank. For the macroprudential policies, I consider two options: one where they are conducted by the central bank with the interest rate as the instrument, and a second one in which there is a macroprudential regulator that uses a countercyclical rule for the LTV as a macroprudential tool.

As this is a microfounded model, it is appropriate to study welfare-related issues. In this setting, there are several channels that affect welfare and that are dependent on mortgage contracts. In new Keynesian models with collateral constraints, there are two types of distortions: sticky prices and credit frictions. Savers prefer policies that alleviate the first distortion, because they own the firms. They are better off in a scenario with price stability, the goal of monetary policy. On the contrary, borrowers' welfare increases when the credit friction distortion is minimized. Then, borrowers may prefer situations that generate inflation or policies that enhance financial stability, namely macroprudential ones. However, these mechanisms may differ depending on whether the prevalent mortgage contract in the economy is a fixed or variable rate. In the variable-rate scenario, monetary policy is more stabilizing because there is a one-for-one link between the policy rate and the borrowing rate. With respect to macroprudential policies, their effectiveness will also depend on whether the economy has fixed or variable rates, because their interaction with monetary policy will have an effect on financial stability.

With the purpose of understanding the dynamics of the baseline model and as a motivation for my study, as a first step I present impulse responses to a technology shock, for the case in which there 
are no macroprudential policies. I find that having variable- or fixed-rate mortgages not only affects the macroeconomic dynamics but also the financial side of the economy. The fixed-rate economy, has a less powerful monetary policy tool but borrowers are more exposed to changes in inflation and house prices, affecting their financial capacity. Therefore, the structure of mortgage contracts should have clear implications, not only for monetary policy reaction but also for macroprudential policies that focus on financial stability. Then, it is relevant to study the optimal implementation of both monetary and macroprudential policies in the context of variable- and fixed-rate mortgages.

Then, I analyze how the optimality of monetary and macroprudential policies changes depending on the mortgage structure of the economy. I define optimal policy as the one that maximizes total welfare. As mentioned, I consider two alternative ways of introducing macroprudential policies. First, I present a simple and automatic rule on the LTV. Following this rule, the LTV would be the instrument of the macroprudential regulator and would react to credit growth. In this way, if the economy is, for instance, entering a credit boom, the LTV will be cut, thus restricting credit in the economy and avoiding excessive credit growth. This rule, which resembles a Taylor rule for monetary policy, serves as a proxy for the macroprudential instruments that have been used by some institutions. ${ }^{2}$ Alternatively, I consider including credit growth in the interest-rate rule of the central bank. In this way, the monetary authority would have one instrument, the interest rate, to take care of two objectives: macroeconomic and financial stability.

The results show that macroprudential policies increase welfare regardless of the mortgage structure prevalent in the economy. Nevertheless, when mortgages are variable rate, an LTV rule combined with monetary policy is preferable to including credit variables in the interest-rate rule. When rates are fixed, using the interest rate as an instrument both for monetary and macroprudential policy delivers higher welfare and stability than having two separate instruments. Interestingly for the fixed-rate case, in which monetary policy is less effective in stabilizing the macroeconomy, it is a more powerful tool for stabilizing the financial system. Sticky prices introduce a first distortion in the economy that can be fixed through monetary policy. However, for the fixed rate case, a simple Taylor rule responding to inflation and output is not able to effectively fix this first distortion. The collateral constraint is introducing an extra distortion that can be fixed by making the regulator respond to credit variables. When credit variables

\footnotetext{
${ }^{2}$ LTV rules have become particularly popular. See for instance, Gruss and Sgherri (2009) who analyze the welfare effects of procyclical LTVs in a real business cycle model with borrowing constraints. Funke and Paetz (2012) use a nonlinear rule on the LTV and find that it can help reduce the transmission of house price cycles to the real economy. In a similar way, Kannan, Rabanal and Scott (2012) examine a monetary policy rule that reacts to prices, output and changes in collateral values with a macroprudential instrument based on the LTV.
} 
are introduced in the Taylor rule, it becomes a more powerful tool because of the volatility of credit with respect to the other two variables and because of the indirect effects that this will have on house prices. This is indeed an example of a theory of second best, given the distortion that the collateral constraint is introducing.

This paper relates to different strands of the literature. First, it introduces heterogeneity in mortgage contracts in the spirit of Rubio (2011), Calza et al. (2013) and Garriga et al. (2015). However, those studies restrict themselves to the effects of the mortgage structure on business cycles and monetary policy, without analyzing the implications for macroprudential policies. Second, it is close to the recent macroprudential literature. On the one hand, it relates with papers in which macroprudential policies interact with monetary policy as in Kannan et al. (2012), Rubio and Carrasco-Gallego (2014), and Angelini et al. (2014). However, none of the above mentioned papers examine how fixed- and variablerate mortgages affect the implementation of macroprudential policies nor affect financial stability. On the other hand, my paper also explores whether monetary and macroprudential policies should be conducted by the same regulator using only one instrument responding to two target variables or two regulators with two different instruments. Following the same line, Beau et al. (2012) claim that it is preferable to have a combination of separate objectives for monetary and macroprudential policies. Rubio and CarrascoGallego (2015) also find that monetary policy should focus on price stability, while macroprudential policy should have financial stability as an instrument. Kannan et al. (2012) experiment with an augmented Taylor rule and an LTV rule as well and find that the results depend on the source of the shock considered. In my paper, I find that having two separate instruments is preferred in the case of variable-rate mortgages but the augmented Taylor rule delivers higher welfare when rates are fixed.

The paper continues as follows. Section 2 explains the basic model I build for the analysis and its dynamics. Section 3 shows the modeling of the macroprudential policies. Section 4 analyzes the normative implications of introducing macroprudential policies and displays the optimal monetary and macroprudential policy mix. Section 5 presents the conclusions. The Appendix contains tables on the empirical evidence mentioned above, sensitivity analyses, extra graphs and model derivations.

\section{The Baseline Model}

I consider an infinite-horizon economy in which households consume, work and demand real estate. There is a representative financial intermediary that provides mortgages and accepts deposits from consumers. 
Firms set prices subject to Calvo (1983)-Yun (1996) nominal rigidity. The monetary authority sets interest rates endogenously, in response to inflation and output, following a Taylor rule.

\subsection{The Consumer's Problem}

There are three types of consumers: unconstrained consumers, constrained consumers who borrow at a variable rate, and constrained consumers who borrow at a fixed rate. Constrained individuals need to collateralize their debt repayments in order to borrow from the financial intermediary. Interest payments for both mortgages and loans cannot exceed a proportion of the future value of the current house stock. In this way, the financial intermediary ensures that borrowers are going to be able to fulfill their debt obligations next period. As in Iacoviello (2005), I assume that constrained consumers are more impatient than unconstrained ones. This assumption ensures that the borrowing constraint is binding, so that constrained individuals do not save and wait until they have the funds to self-finance their consumption. This generates an economy in which households divide into borrowers and savers. Furthermore, borrowers are split into two groups: those who borrow at a fixed rate and those who borrow at a variable rate. The proportion of each type of borrower is fixed and exogenous. All households derive utility from consumption, and housing services are assumed proportional to the housing stock and leisure.

\subsubsection{The Financial Intermediary}

Consider a financial intermediary that accepts deposits from savers, and extends both fixed- and variablerate loans to borrowers. ${ }^{3}$ I assume a competitive framework, and thus the intermediary takes the variable-interest rate as given. The profits of the financial intermediary are defined as:

$$
F_{t}=\alpha R_{t-1} b_{t-1}^{c v}+(1-\alpha) \bar{R}_{t-1} b_{t-1}^{c f}-R_{t-1} b_{t-1}^{u}
$$

where $F_{t}$ represents the profits of the financial intermediary, $\alpha$ is the proportion of variable rates, $R_{t-1}$ is the gross policy rate set by the central bank, and $b_{t-1}^{c v}$ and $b_{t-1}^{c f}$ are one-period variable- and fixed-rate mortgages, respectively. ${ }^{4} b_{t-1}^{u}$ represent deposits.

In equilibrium, aggregate borrowings and savings must be equal, that is:

\footnotetext{
${ }^{3}$ In countries where fixed-rate mortgages are most extensively used, financial intermediaries pass on the loans to investors with long-term liabilities (such as pension funds and life-insurance companies). Short-term deposits are predominantly used to finance mortgages in countries where variable-rate mortgages are commonly used. These institutional features are beyond the scope of this paper.

${ }^{4}$ Note that in this model mortgages are a flow variable.
} 


$$
\alpha b_{t}^{c v}+(1-\alpha) b_{t}^{c f}=b_{t}^{u} .
$$

Substituting (2) into (1), we obtain:

$$
F_{t}=(1-\alpha) b_{t-1}^{c f}\left(\bar{R}_{t-1}-R_{t-1}\right)
$$

In order for the two types of mortgage to be offered, the fixed interest rate has to be such that the intermediary is indifferent between lending at a variable or fixed rate. ${ }^{5}$ Hence, the expected discounted profits that the intermediary obtains by lending new debt in a given period at a fixed interest rate must be equal to the expected discounted profits the intermediary would obtain by lending it at a variable rate: ${ }^{6}$

$$
E_{\tau} \sum_{i=\tau+1}^{\infty} \beta^{i-\tau} \Lambda_{\tau, i} \bar{R}_{\tau}^{*}=E_{\tau} \sum_{i=\tau+1}^{\infty} \beta^{i-\tau} \Lambda_{\tau, i} R_{i-1}
$$

where $\Lambda_{t, i}=\left(\frac{C_{t}^{u}}{C_{t+i}^{u}}\right)$ is the unconstrained consumer-relevant discount factor. As the financial intermediary is owned by the savers, their stochastic discount factor is applied to the financial intermediary's problem. ${ }^{7}$ Note that, as stated previously, variable-rate debt is one period but the portion of new debt acquired at a fixed rate is associated with a long-term contract. ${ }^{8}$ As the agent is infinitely lived, the financial intermediary considers an infinitely lasting maturity in these calculations. ${ }^{9}$

We can obtain the equilibrium value of the fixed rate in period $\tau$ from expression (4):

$$
\bar{R}_{\tau}^{*}=\frac{E_{\tau} \sum_{i=\tau+1}^{\infty} \beta^{i-\tau} \Lambda_{\tau, i} R_{i-1}}{E_{\tau} \sum_{i=\tau+1}^{\infty} \beta^{i-\tau} \Lambda_{\tau, i}} .
$$

Equation (5) states that, for every new debt issued at date $\tau$, there is a different fixed interest rate

\footnotetext{
${ }^{5}$ The steady-state fixed rate equals the steady-state variable rate and therefore the steady state of the model is not affected by this specification.

${ }^{6}$ The fixed-rate loan is priced following this nonarbitrage condition, not by applying the prices of zero-coupon bonds to the future cash flows from the new loan.

${ }^{7}$ Note that there is no difference between having the financial intermediary as a separate agent or putting these decisions with the patient household.

${ }^{8}$ The long-term contract relates primarily to the interest rate, rather than the debt being explicitly amortized.

${ }^{9}$ Calza et al. (2010) also develop a model in which the financial intermediary offers fixed- and variable-rate mortgages. However, in their model, the two types of mortgages do not coexist. For them, the fixed-rate loan is a two-period contract, whereas the variable-rate loan is for one period. In my model, I allow for the two mortgages to be offered in order to be able to study intermediate cases in which a mix of the two types of contracts are present in the economy.
} 
that has to be equal to a discounted average of future variable interest rates. Note that this is not a condition on the stock of debt, but on the new amount obtained in a given period. New debt at a given point in time is associated with a different fixed interest rate. Both the fixed interest rate in period $\tau$ and the new amount of debt in period $\tau$ are fixed for all future periods. However, the fixed interest rate varies with the date the debt was issued, so that in every period there is a new fixed interest rate associated with new debt in this period. If we consider fixed-rate loans to be long term, the financial intermediary obtains interest payments every period from the whole stock of debt, not only from the new debt. Hence, we can define the aggregate fixed interest rate as being the one the financial intermediary effectively charges every period for the whole stock of mortgages. This aggregate fixed interest rate is a function of all past fixed interest rates on past debt, together with the current period equilibrium fixed interest rate on the new debt. Therefore, the effective fixed interest rate that the financial intermediary charges for the stock of fixed-rate debt every period is:

$$
\bar{R}_{t}=\left\{\begin{array}{c}
\frac{\bar{R}_{t-1} b_{t-1}^{c f}+\bar{R}_{t}^{*}\left(b_{t}^{c f}-b_{t-1}^{c f}\right)}{b_{t}^{c f}} \text { if } b_{t}^{c f}>b_{t-1}^{c f} \\
\bar{R}_{t-1} \text { if } b_{t}^{c f} \leq b_{t-1}^{c f}
\end{array}\right\} .
$$

Equation (6) states that the fixed interest rate that the financial intermediary is actually charging today is an average of what it charged last period for the previous stock of mortgages and what it charges this period for the new amount. ${ }^{10}$ In the case that there is no new debt, the fixed interest rate will be equal to last period's. ${ }^{11}$ Then, in the same way that variable rates are revised every period, fixed rates are revised by including the new optimal fixed interest rate for the new debt originated in this period. Importantly, this assumption is not crucial for the results. Both $\bar{R}_{\tau}^{*}$ and $\bar{R}_{t}$ are practically unaffected by interest rate shocks. ${ }^{12}$ This assumption is a way to make the model compatible with the fact that fixed-rate loans are not one-period assets but are longer-term ones. ${ }^{13}$ Therefore, even though strictly speaking all mortgages are one-period loans in this model, equation (6) makes fixed-rate loans long-term ones. In this case, if there is new borrowing, this will add to the existing stock of loans at a new optimal

\footnotetext{
${ }^{10}$ This expression can be interpreted in a similar way as in Calza et al. (2010). In their model, the fixed rate loan is repaid in two periods. Here, while the contract is of infinite maturity, I also divide payments into two blocks: the new payments made this period for new loans and the payments for the old loans.

${ }^{11}$ Note that, if $\bar{R}_{t}>\bar{R}_{t}^{*}$, remortgaging to a lower $\bar{R}_{t}^{*}$ is not allowed in the model. The agent cannot repay the most expensive mortgages first either.

${ }^{12}$ When the model is log-linearized, the non-linearity disappears because the fixed interest rate does not move from the steady-state interest rate. Please see the Appendix for details.

${ }^{13}$ In the real world, variable-rate mortgages are also long-term loans. That is, both loans are amortized over a long period of time. The only difference is that the interest payments on adjustable-rate mortgages are variable. In the model, variable-rate mortgages are modeled as one-period loans.
} 
fixed interest rate. If there is no new debt, the interest rate that is charged for the existing stock does not change. The contract is set at a specific point in time and lasts for as many periods as there is no new debt. If there is new debt, a new fixed interest rate is calculated and an average interest rate composed of the past interest rate and this new interest rate will be applied to the whole stock of debt. This new interest rate will also last for as many periods as there is no new debt.

As noted above, any profits from financial intermediation are rebated to the unconstrained consumers every period. Even if the financial intermediary is competitive and profits are expected to be zero, if there is a shock at a given point in time, the fact that only the variable interest rate is directly affected can generate nonzero profits.

\subsubsection{Unconstrained Consumers (Savers)}

Unconstrained consumers maximize:

$$
\max E_{0} \sum_{t=0}^{\infty} \beta^{t}\left(\ln C_{t}^{u}+j_{t} \ln H_{t}^{u}-\frac{\left(L_{t}^{u}\right)^{\eta}}{\eta}\right)
$$

where the superscript $u$ stands for "unconstrained," $E_{0}$ is the expectation operator, $\beta \in(0,1)$ is the discount factor, and $C_{t}^{u}, H_{t}^{u}$ and $L_{t}^{u}$ are consumption at $t$, the stock of housing and hours worked, respectively; $1 /(\eta-1)$ is the labor supply elasticity, $\eta>0 . j_{t}$ represents the weight of housing in the utility function. I assume that $\log \left(j_{t}\right)=\log (j)+u_{J t}$, where $u_{J t}$ follows an autoregressive process. A shock to $j_{t}$ represents a shock to the marginal utility of housing. These shocks directly affect housing demand and therefore can be interpreted as a proxy for exogenous disturbances to house prices.

The budget constraint is:

$$
C_{t}^{u}+q_{t} H_{t}^{u}+b_{t}^{u} \leq q_{t} H_{t-1}^{u}+w_{t}^{u} L_{t}^{u}+\frac{R_{t-1} b_{t-1}^{u}}{\pi_{t}}+F_{t}^{v}+S_{t}^{v},
$$

where $q_{t}$ is the real housing price and $w_{t}^{u}$ is the real wage for unconstrained consumers who can buy houses or sell them at the current price $q_{t}$. I assume zero housing depreciation for simplicity. As we will see, this group will choose not to borrow at all; they are the savers in this economy. $b_{t}^{u}$ is the amount they save. They receive interest $R_{t-1}$ for their savings. $\pi_{t}$ is inflation in period $t . S_{t}$ and $F_{t}$ are lump-sum profits received from the firms and the financial intermediary, respectively. We can think of these consumers as the wealthy agents in the economy, who own the firms and the financial intermediary. 
The first-order conditions for this unconstrained group are:

$$
\begin{gathered}
\frac{1}{C_{t}^{u}}=\beta E_{t}\left(\frac{R_{t}}{\pi_{t+1} C_{t+1}^{u}}\right), \\
w_{t}^{u}=\left(L_{t}^{u}\right)^{\eta-1} C_{t}^{u}, \\
\frac{j_{t}}{H_{t}^{u}}=\frac{1}{C_{t}^{u}} q_{t}-\beta E_{t} \frac{1}{C_{t+1}^{u}} q_{t+1} .
\end{gathered}
$$

Equation (9) is the Euler equation for consumption, equation (10) is the labor-supply condition, and equation (11) is the Euler equation for housing. This states that the benefits from consuming housing must be equal to the costs at the margin.

\subsubsection{Constrained Consumers (Borrowers)}

Constrained consumers are of two types: those who borrow at a variable rate and those who do so at a fixed rate. The difference between them is simply the interest rate they face. The fixed-rate borrower faces $\bar{R}_{t}$, set by the financial intermediary, whereas the variable-rate counterpart faces $R_{t}$, set by the central bank. The proportion of variable-rate consumers is fixed and exogenous and equal to $\alpha \in[0,1] .{ }^{14}$

Constrained and unconstrained consumers are different in the way they discount the future. Constrained consumers are more impatient than unconstrained ones. I assume that constrained consumers face a limit on the debt they can acquire. The maximum amount they can borrow is proportional to the value of their collateral, in this case the stock of housing. That is, the debt repayment next period cannot exceed a proportion of tomorrow's value of today's stock of housing:

$$
\begin{gathered}
E_{t} \frac{R_{t}}{\pi_{t+1}} b_{t}^{c v} \leq k_{t} E_{t} q_{t+1} H_{t}^{c v}, \\
E_{t} \frac{\bar{R}_{t}}{\pi_{t+1}} b_{t}^{c f}
\end{gathered}
$$

\footnotetext{
${ }^{14}$ This proportion is held fixed because it is not the aim of this paper to explain how the decision between fixed and variable-rate mortgages is made. Although this proportion can vary in reality, there is evidence that it fluctuates around a constant mean, for long periods of time, which is higher or lower depending on the country. The European Mortgage Federation (EMF) highlights that cultural differences play an important role for the predominant type of mortgage contract in a country. They are linked to real estate law, borrowers' risk aversion, funding system or frequency of house moves. Thus, in this paper, we take these cross-country differences as due to institutional, historical or cultural factors, out of the scope of this model.
} 
where (12) represents the collateral constraint for the variable-rate constrained consumer and (13) is the constraint for the fixed-rate one. ${ }^{15}$ The superscript $c v$ stands for "constrained variable," while $c f$ stands for "constrained fixed." $k_{t}$ represents a proxy for the LTV and, as we will see, it is the instrument of the macroprudential authority. As we have seen with the problem of the financial intermediary, $\bar{R}_{t}$ is an aggregate interest rate that contains information on all the past fixed interest rates associated with past debt. Each period, this aggregate interest rate is updated with a new interest rate linked to the new amount of debt originated in that period.

Without loss of generality, I present the problem for the variable-rate borrower, because the one for the fixed-rate borrower is symmetric. Variable-rate borrowers maximize their lifetime utility function:

$$
\max E_{0} \sum_{t=0}^{\infty} \widetilde{\beta}^{t}\left(\ln C_{t}^{c v}+j_{t} \ln H_{t}^{c v}-\frac{\left(L_{t}^{c v}\right)^{\eta}}{\eta}\right),
$$

subject to the budget constraint:

$$
C_{t}^{c v}+q_{t} H_{t}^{c v}+\frac{R_{t-1} b_{t-1}^{c v}}{\pi_{t}} \leq q_{t} H_{t-1}^{c v}+w_{t}^{c v} L_{t}^{c v}+b_{t}^{c v}
$$

and (12), the collateral constraint. ${ }^{16}$ Note that variable-rate borrowers repay all debt every period and acquire new debt at the current new interest rate. This assumption implies that the interest rate on variable-rate mortgages is revised every period for the whole stock of debt and changed according to the policy rate. ${ }^{17}$ In order to make the problem for fixed-rate borrowers symmetric and analogous to the existing models with borrowing constraints, I assume the same debt-repayment structure for this type of borrower. Obviously, fixed-rate contracts are not revised every period. However, to make the model more realistic but still tractable, the fixed interest rate will be such that a revised fixed rate will be applied only on new debt, keeping constant the interest rate applied to existing debt. In this way, I reconcile the structure of the model with the fact that fixed-rate contracts are long term. ${ }^{18}$

\footnotetext{
${ }^{15}$ Garriga et al. (2005) and Alpanda et al. (2014) take a slightly different approach for their borrowing constraint. This strand of the literature differentiates the effects of policies that apply only to new lending as opposed to all existing mortgage debt. The constraint on borrower households is imposed on the flow rather than the stock of household debt, and new mortgage loans are modeled as fixed rate. This feature captures the notion that a significant share of new mortgage loans in the real world are adjustable-rate loans, and some fixed-rate mortgages are refinanced before the end of their amortization period. With this specification, an increase in debt in this period leads to a tightening of the borrowing constraint next period as well. However, with full amortization, both borrowing constraints would be equivalent.

${ }^{16}$ We will see from the firm's problem that $w_{t}^{c v}=w_{t}^{c f}=w_{t}^{c}$.

${ }^{17}$ This assumption is consistent with reality, in which variable interest rates are revised very frequently and changed according to an interest-rate index tied to the interest rate set by the central bank.

${ }^{18}$ Another option would be to have an overlapping generations model in which we are able to keep track of the debt issued in each period. However, the model would become more complex and less comparable with the standard collateral-constraint DSGE models such as that described by Iacoviello (2005).
} 
As noted above, constrained consumers are more impatient than unconstrained ones, so that $\widetilde{\beta}<\beta$. This assumption is crucial for the borrowing constraint to be binding and therefore, for there to be both borrowers and savers in the economy.

The first-order conditions for variable-rate constrained consumers are:

$$
\begin{gathered}
\frac{1}{C_{t}^{c v}}=\widetilde{\beta} E_{t}\left(\frac{R_{t}}{\pi_{t+1} C_{t+1}^{c v}}\right)+\lambda_{t}^{c v} R_{t} \\
w_{t}^{c v}=\left(L_{t}^{c v}\right)^{\eta-1} C_{t}^{c v} \\
\frac{j_{t}}{H_{t}^{c v}}=\frac{1}{C_{t}^{c v}} q_{t}-\widetilde{\beta} E_{t}\left(\frac{1}{C_{t+1}^{c v}} q_{t+1}\right)-\lambda_{t}^{c v} k_{t} E_{t}\left(q_{t+1} \pi_{t+1}\right) .
\end{gathered}
$$

These first-order conditions differ from those of the unconstrained individuals. In the case of constrained consumers, the Lagrange multiplier on the borrowing constraint $\left(\lambda_{t}^{c v}\right)$ appears in equations (16) and (18). ${ }^{19}$ From the Euler equation for the consumption of unconstrained consumers, we know that $R=1 / \beta$ in the steady state. If we combine this result with the Euler equation for the consumption of the constrained individuals we have that $\lambda^{c v}=(\beta-\widetilde{\beta}) / C^{c v}>0$ in the steady state. This means that the borrowing constraint holds with equality in the steady state. As we log-linearize the model around the steady state and assume that uncertainty is low, we can generalize this result to off-steady-state dynamics. Then, the borrowing constraint is always binding, so that constrained individuals borrow the maximum amount they are allowed to and unconstrained consumers are never in debt. ${ }^{20}$

Given the borrowing amount implied by (12) at equality, consumption of the variable-rate constrained individuals can be determined by their flow of funds:

$$
C_{t}^{c v}=w_{t}^{c v} L_{t}^{c v}+b_{t}^{c v}+q_{t}\left(H_{t-1}^{c v}-H_{t}^{c v}\right)-\frac{R_{t-1} b_{t-1}^{c v}}{\pi_{t}}
$$

and the first-order condition for housing becomes:

$$
\frac{j_{t}}{H_{t}^{c v}}=\frac{1}{C_{t}^{c v}}\left(q_{t}-\frac{k_{t} E_{t}\left(q_{t+1} \pi_{t+1}\right)}{R_{t}}\right)-\widetilde{\beta} E_{t}\left(\frac{1}{C_{t+1}^{c v}}\left(1-k_{t}\right) q_{t+1}\right)
$$

\footnotetext{
${ }^{19}$ In the log-linearized versions of the Euler equations for both consumer types, I include a demand shock reflecting exogenous changes in demand. See equations (46) and (47) in the Appendix.

${ }^{20}$ This is a typical assumption for this type of model. See Appendix C of Iacoviello (2005) for a detailed analysis of when constraints bind.
} 


\section{$2.2 \quad$ Firms}

\subsubsection{Final Goods Producers}

There is a continuum of identical final goods producers that aggregate intermediate goods according to the production function:

$$
Y_{t}=\left[\int_{0}^{1} Y_{t}(z)^{\frac{\varepsilon-1}{\varepsilon}} d z\right]^{\frac{\varepsilon}{\varepsilon-1}},
$$

where $\varepsilon>1$ is the elasticity of substitution between intermediate goods. The final good firm chooses $Y_{t}(z)$ to minimize its costs, resulting in demand of intermediate good $z$ :

$$
Y_{t}(z)=\left(\frac{P_{t}(z)}{P_{t}}\right)^{-\varepsilon} Y_{t}
$$

The price index is then given by:

$$
P_{t}=\left[\int_{0}^{1} P_{t}(z)^{1-\varepsilon} d z\right]^{\frac{1}{\varepsilon-1}}
$$

Market clearing for the final good requires:

$$
Y_{t}=C_{t}=C_{t}^{u}+C_{t}^{c}
$$

\subsubsection{Intermediate Goods Producers}

The intermediate goods market is monopolistically competitive. Following Iacoviello (2005), intermediate goods are produced according to the production function:

$$
Y_{t}(z)=A_{t} L_{t}^{u}(z)^{\gamma} L_{t}^{c}(z)^{(1-\gamma)}
$$

where $\gamma \in[0,1]$ measures the relative size of each group in terms of labor. This Cobb-Douglas production function implies that the labor efforts of constrained and unconstrained consumers are not perfect substitutes. This specification is analytically tractable and allows for closed-form solutions for the steady state of the model. This assumption can be economically justified by the fact that savers are the managers of the firms and their wages are higher than those of the borrowers. ${ }^{21}$ Experimenting with a production

\footnotetext{
${ }^{21}$ It could also be interpreted as the savers being older than the borrowers, and therefore more experienced.
} 
function in which labor hours for both types of consumers are substitutes leads to very similar results in terms of model dynamics. Under the Cobb-Douglas specification, each household has mass one. $\gamma$ is a constant that represents the labor-income share of the patient household and $L_{t}^{u}$ are total hours worked by the patient household. In the alternative specification, one needs to define the fraction of agents in the population, assuming that $\omega$ is the fraction of savers. Then, $\omega L_{t}^{u}$ represents the total hours worked by the patient household. Therefore, both specifications are very similar but, while $\gamma$ represents the economic size of savers, $\omega$ would correspond to their absolute size. ${ }^{22}$

$A_{t}$ represents technology and it follows the following autoregressive process:

$$
\log \left(A_{t}\right)=\rho_{A} \log \left(A_{t-1}\right)+u_{A t}
$$

where $\rho_{A}$ is the autoregressive coefficient and $u_{A t}$ is a normally distributed shock to technology.

Labor demand is determined by:

$$
\begin{gathered}
w_{t}^{u}=\frac{1}{X_{t}} \gamma \frac{Y_{t}}{L_{t}^{u}}, \\
w_{t}^{c}=\frac{1}{X_{t}}(1-\gamma) \frac{Y_{t}}{L_{t}^{c}},
\end{gathered}
$$

where $X_{t}$ is the markup, or the inverse of marginal cost. ${ }^{23}$

The price-setting problem for the intermediate good producers is a standard Calvo-Yun setting. An intermediate good producer sells its good at price $P_{t}(z)$, and $1-\theta, \in[0,1]$, is the probability of being able to change the sale price in every period. The optimal reset price $P_{t}^{*}(z)$ solves:

$$
\sum_{k=0}^{\infty}(\theta \beta)^{k} E_{t}\left\{\Lambda_{t, k}\left[\frac{P_{t}^{*}(z)}{P_{t+k}}-\frac{\varepsilon /(\varepsilon-1)}{X_{t+k}}\right] Y_{t+k}^{*}(z)\right\}=0 .
$$

The aggregate price level is then given by:

$$
P_{t}=\left[\theta P_{t-1}^{1-\varepsilon}+(1-\theta)\left(P_{t}^{*}\right)^{1-\varepsilon}\right]^{1 /(1-\varepsilon)}
$$

Using (28) and (29), and log-linearizing, we can obtain a standard forward-looking new Keynesian Phillips curve that relates inflation positively to future inflation and negatively to the markup. To

\footnotetext{
${ }^{22}$ The full derivation of this alternative specification is available upon request.

${ }^{23}$ Symmetry across firms allows us to write the demands without the index $z$.
} 
make the behavior of inflation more realistic, I have added a lagged inflation term in the new Keynesian Phillips curve (see equation 53 in the Appendix). ${ }^{24}$

\subsection{Aggregate Variables}

Given the fraction $\alpha$ of variable-rate borrowers, we can define aggregates across constrained consumers as $C_{t}^{c} \equiv \alpha C_{t}^{c v}+(1-\alpha) C_{t}^{c f}, L_{t}^{c} \equiv \alpha L_{t}^{c v}+(1-\alpha) L_{t}^{c f}, H_{t}^{c} \equiv \alpha H_{t}^{c v}+(1-\alpha) H_{t}^{c f}, b_{t}^{c} \equiv \alpha b_{t}^{c v}+(1-\alpha) b_{t}^{c f}$.

Therefore, the economy-wide aggregates are: $C_{t} \equiv C_{t}^{u}+C_{t}^{c}, L_{t} \equiv L_{t}^{u}+L$, and $H_{t} \equiv H_{t}^{u}+H_{t}^{c}$. In this model, aggregate supply of housing is fixed, so that market clearing requires $H_{t}=H{ }^{25}$

\subsection{Monetary Policy}

The model is closed with a Taylor rule with interest-rate smoothing, to describe the conduct of monetary policy by the central bank: ${ }^{26}$

$$
R_{t}=\left(R_{t-1}\right)^{\rho}\left[\pi_{t}^{\left(1+\phi_{\pi}\right)}\left(Y_{t} / Y_{t-1}\right)^{\phi_{y}} R\right]^{1-\rho} \varepsilon_{R t}
$$

where $0 \leq \rho \leq 1$ is the parameter associated with interest-rate inertia. $\phi_{\pi}$ and $\phi_{y}>0$ measure the response of interest rates to current inflation and output growth, respectively. ${ }^{27} R$ is the steady-state value of the interest rate. $\varepsilon_{R t}$ is a white noise shock with zero mean and variance $\sigma_{\varepsilon}^{2}$.

\subsection{Dynamics}

\subsubsection{Parameter Values}

I linearize the equilibrium equations around the steady state. Details are shown in the Appendix. For calibration, I consider the following parameter values: the discount factor, $\beta$, is set to 0.99 so that the annual interest rate is $4 \%$ in the steady state. The discount factor for borrowers, $\widetilde{\beta}$, is set to 0.98 . Lawrance (1991) estimates discount factors for poor consumers of between 0.95 and 0.98 at a quarterly

\footnotetext{
${ }^{24}$ I have followed McCallum (2001) for the specification of the Phillips curve.

${ }^{25}$ This assumption provides an easy way to specify the supply of housing and to have variable prices. A two-sector model with production of housing would not generate qualitatively different results.

${ }^{26}$ This is a realistic policy benchmark for most industrialized countries. A more realistic rule would also include output but it complicates developing intuition about the workings of the model. Furthermore, the estimation results suggest a small response to the output gap in the last two decades (see Clarida, Galí and Gertler, 2000). Nevertheless, robustness checks to this specification will be performed.

${ }^{27}$ Including deviations of output from the steady state instead of output growth delivers more indeterminacy areas, especially for the case of fixed rates. Thus, in order to compare the cases of fixed and variable rates, it is more convenient to stick to a Taylor rule with a wider determinacy range for both cases, that is, the one containing output growth, because otherwise, the fixed-rate case becomes too restrictive.
} 
frequency. The results are not sensitive to different values within this range. ${ }^{28}$ This value of $\widetilde{\beta}$ is low enough to endogenously divide the economy into borrowers and savers. The weight of housing in the utility function, $j$, is set to 0.1 in order for the ratio of housing wealth to GDP in the steady state to be consistent with the data. This value of $j$ implies a ratio of approximately 1.40 , which is in line with the Flow of Funds data. ${ }^{29}$ I set $\eta=2$, implying a value of the labor supply elasticity of $1 .{ }^{30}$ For the LTV, I selected $k_{S S}=0.9$, which is consistent with the evidence that in recent years borrowing-constrained consumers borrowed on average more than $90 \%$ of the value of their house. ${ }^{31}$ The labor income share of unconstrained consumers, $\gamma$, is set to 0.64 , following the estimate in Iacoviello (2005). ${ }^{32}$ I selected a value of 6 for $\varepsilon$, the elasticity of substitution between intermediate goods. This value implies a steady-state markup of 1.2 . The probability of not changing prices, $\theta$, is set to 0.75 , implying that prices change every four quarters. The inflation persistence parameter $\phi$ is set to 0.5 , as suggested by the approach of Fuhrer and Moore (1995). For the Taylor rule parameters, I use $\rho=0.8, \phi_{\pi}=0.5$ and $\phi_{y}=0.5$. The first value reflects a realistic degree of interest-rate smoothing. ${ }^{33}$ The second and third values are consistent with the original parameter proposed by Taylor in 1993. For $\alpha$, I consider two polar cases for comparison. In the first case, the proportion of variable-rate mortgages in the economy is 0 , that is, all constrained consumers in the economy borrow at a fixed rate. In the second case, the proportion of variable-rate mortgages is 1 . For the calibration of the standard deviations and persistence of the shocks, I mainly follow the estimates of Iacoviello (2005) and Iacoviello and Neri (2010). The technology shock standard deviation is set to $1 \%$, as in Iacoviello and Neri (2010), with 0.9 persistence. ${ }^{34}$ Monetary policy shocks are represented by a $0.29 \%$ increase in the interest rate on a quarterly basis (as in Iacoviello (2005)) House price shocks have 0.95 degrees of persistence. ${ }^{35}$ I set the size of the shock to the housing-demand parameter at $24.89 \%$, consistent with Iacoviello (2005). The standard deviation of the demand shock is

\footnotetext{
${ }^{28}$ Please, see Table A2 in the Appendix where I show this is the case. We see that volatilities barely change for the variable-rate case and very little for the fixed-rate scenario.

${ }^{29}$ See Table B.101. In this model, consumption is the only component of GDP. To make the ratio comparable with the data, I multiply it by 0.6 , which is approximately what nondurable consumption and services account for in the GDP, according to the data in the NIPA tables. Alpanda and Zubairy (2014) report values using quarterly GDP.

${ }^{30}$ Microeconomic estimates usually suggest values in the range of 0 and 0.5 (for males). Domeij and Flodén (2006) show that in the presence of borrowing constraints these estimates could have a downward bias of $50 \%$.

${ }^{31}$ We can identify constrained consumers as those who borrow more than $80 \%$ of their home value. In the US, among those borrowers, the average LTV exceeded $90 \%$ for the period 1973-2006. See the data from the Federal Housing Finance Board.

${ }^{32}$ For a robustness check on this parameter, I present Table A3 in the Appendix. Volatilities do not change dramatically across values, although the volatility of credit increases in the fixed-rate case for low and high values of this parameter.

${ }^{33}$ See McCallum (2001).

${ }^{34}$ This high persistence value for technology shocks is consistent with what is commonly reported in the literature. Smets and Wouters (2002) estimate a value of 0.822 for this parameter in Europe; Iacoviello and Neri (2010) estimate it to be 0.93 for the US.

${ }^{35}$ The persistence of the house price shock is consistent with the estimates in Iacoviello and Neri (2010).
} 
set to 1\%, as in Iacoviello and Neri (2010). As in Rabanal (2004) and Iacoviello and Neri (2010), the degree of persistence of the demand shock is set to 0.80 . Table 1 shows a summary of the parameter values.

\begin{tabular}{|c|c|c|}
\hline \multicolumn{2}{|c|}{ Table 1: Parameter values } \\
\hline \hline$\beta$ & .99 & Discount factor for savers \\
\hline$\widetilde{\beta}$ & .98 & Discount factor for borrowers \\
\hline$j$ & .1 & Weight of housing in utility function \\
\hline$\eta$ & 2 & Parameter associated with labor elasticity \\
\hline$k_{S S}$ & .9 & LTV \\
\hline$\gamma$ & .64 & Labor share for savers \\
\hline$\alpha$ & $0 / 1$ & Proportion of variable-rate borrowers \\
\hline$X$ & 1.2 & Steady-state markup \\
\hline$\theta$ & .75 & Probability of not changing prices \\
\hline$\rho_{A}$ & .9 & Technology persistence \\
\hline$\rho$ & .8 & Interest-rate-smoothing parameter in Taylor rule \\
\hline$\phi_{\pi}$ & .5 & Inflation parameter in Taylor rule \\
\hline
\end{tabular}

\subsubsection{Impulse Responses}

To gain some insight into the dynamics of the model before studying macroprudential policies, Figure 1 presents impulse responses to a $1 \%$ positive shock to technology with 0.9 degrees of persistence. We see that the economy responds slightly more strongly after a technology shock when the majority of its borrowers have a fixed-rate mortgage.

In particular, we can see in Figure 1 that a positive technology shock increases output and lowers prices. As a result, nominal rates decrease. However, for the fixed-rate case, inflation drives the real rate and therefore it increases. House prices, which move inversely with the interest rate, increase in the case of the variable-rate economy but do not increase as much in the fixed-rate one. For variable-rate consumers, the increase in house prices and the decrease in the interest rate make borrowing increase. Furthermore, because housing is now a more valuable asset, variable-rate borrowers use this borrowing to increase both housing and consumption goods. However, for fixed-rate consumers, the increase in the real rate together with the fact that house prices are not increasing as much as in the variable-rate case make borrowing decrease. Fixed-rate borrowers prefer to decrease housing purchases in favor of 

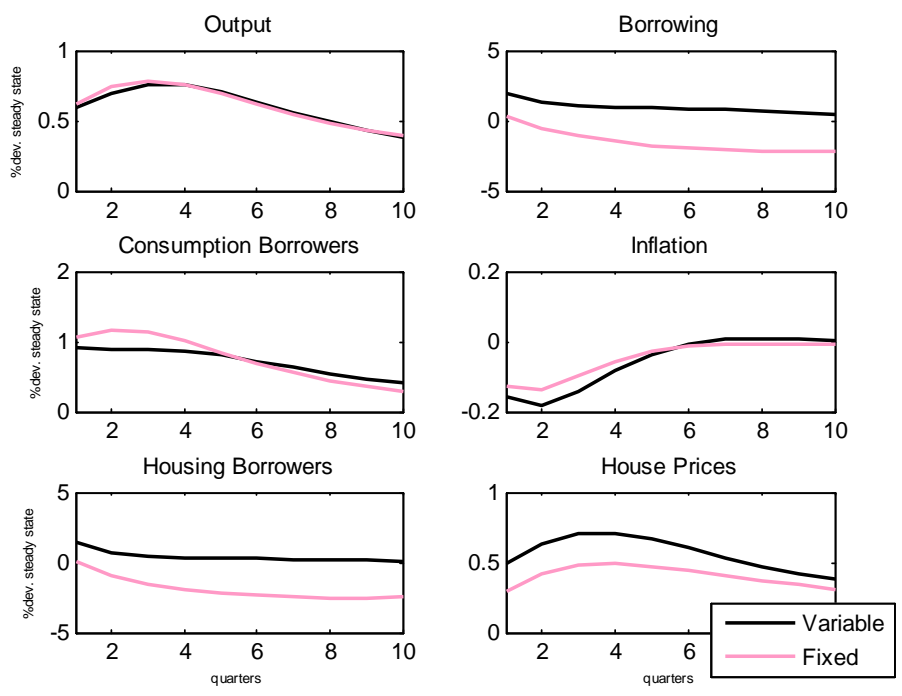

Figure 1: Impulse responses to a technology shock.

consumption goods and this is why output ends up increasing by slightly more in the fixed-rate scenario.

We can see from the dynamics of the model that having variable- or fixed-rate mortgages does not only affect the macroeconomy but also the financial side. The fixed-rate economy has a less powerful monetary policy tool, but borrowers are more exposed to changes in inflation and house prices and thus this is going to affect credit. Therefore, the structure of mortgage contracts has clear implications, not only for monetary policy reaction and for macro variables but also for house prices and borrowing. Thus, it seems clear that when including macroprudential policies, the mortgage contracts that are prevalent in the economy will affect their implementation, because the macroprudential regulator cares about financial stability.

\section{$3 \quad$ Modeling Macroprudential Policies}

For the macroprudential policy, I will compare two options. The first one is a rule on the LTV, so that this variable responds to credit growth. The second one is an extended Taylor rule so that the interest rate, apart from responding to inflation and output, also responds to credit growth.

The first case corresponds to a situation in which macroprudential supervision should involve a regulatory agency, different from the central bank or within the central bank, that uses a different instrument for macroprudential purposes. The second case represents a world in which macroprudential and monetary policies are integrated and assigned to the central bank, which uses only one instrument, 
the interest rate, to achieve both macroeconomic and financial stability. In this case, the objectives of monetary policy should be expanded to include financial stability.

\subsection{LTV Rule}

As an approximation to a realistic macroprudential policy, I consider a simple rule for the LTV. In standard models, the LTV is a fixed parameter that is not affected by economic conditions. However, we can think of regulations of LTVs as a way to moderate credit booms. When the LTV is high, the collateral constraint is less tight. Furthermore, because the constraint is binding, borrowers will borrow as much as they are allowed to. Lowering the LTV tightens the constraint and therefore restricts the loans that borrowers can obtain. Recent research on macroprudential policies has proposed simple rules for the LTV that inversely react to variables such as the growth rates of GDP, credit growth, the creditto-GDP ratio or house prices. These rules are a simple illustration of how a macroprudential policy could work in practice. Here, we assume that there exists a macroprudential simple rule for the LTV, so that it responds to credit growth: ${ }^{36}$

$$
k_{t}=k_{S S}\left(b_{t} / b_{t-1}\right)^{-\phi_{b}^{k}}
$$

where $k_{S S}$ is the steady-state value for the LTV. $\phi_{b}^{k} \geq 0$ measures the response of the LTV to credit growth. This type of rule would deliver a lower LTV in booms, when credit is growing, therefore restricting the credit in the economy and avoiding a credit boom caused by good economic conditions.

\subsection{Macroprudential Taylor Rule}

Here, I am considering the case in which the central bank adopts a macroprudential approach and monitors credit variables. Then, I extend the Taylor rule to not only respond to inflation and output growth but also to credit growth.

$$
R_{t}=\left(R_{t-1}\right)^{\rho}\left[\pi_{t}^{\left(1+\phi_{\pi}\right)}\left(Y_{t} / Y_{t-1}\right)^{\phi_{y}}\left(b_{t} / b_{t-1}\right)^{\phi_{b}} R\right]^{1-\rho} \varepsilon_{R t} .
$$

\footnotetext{
${ }^{36}$ This rule captures the spirit of Basel III regulations on macroprudential policies. According to BCBS (2010), macroprudential policies should aim at protecting the economy from periods of excess aggregate credit growth, because they have often been associated with the build-up of system-wide risk. Therefore, it recommends national authorities to closely monitor this variable, i.e., credit growth. The committee also states that other variables such as asset prices or credit spreads could be useful indicators but are sometimes misleading because they can be affected by other factors not related to fundamentals.
} 
Thus, we are giving the central bank a way to implement a macroprudential policy. Note that increasing the interest rate when credit is growing means restricting credit booms in the economy, because debt repayments are increasing. Therefore, in this case, the goals of the central bank are extended to also include financial stability.

\section{Normative Analysis}

In this section, I introduce the above mentioned macroprudential policies and study their implications for welfare and their optimal implementation. In order to do that, first I present a measure for welfare. Then, using this measure, I analyze the optimality of monetary and macroprudential policies for both fixed- and variable-rate mortgage economies and present impulse-responses using the optimized values. ${ }^{37}$

In new Keynesian models with collateral constraints, there are two types of distortions: sticky prices and credit frictions. Savers prefer policies that alleviate the first distortion, because they own the firms. They are better off in a scenario with price stability, the goal of monetary policy. However, borrowers' welfare increases when the credit friction distortion is minimized. Then, borrowers may prefer situations that generate inflation, because in this case, the collateral constraint is relaxed through lower real debt repayments. On the one hand, monetary policy has effects on the constraint directly through the interest rate that borrowers have to pay and indirectly through house prices, which makes collateral more or less valuable. On the other hand, macroprudential policies that deliver higher financial stability also lower the negative effects of the credit friction, because they provide borrowers with a scenario in which their consumption is smoother.

However, these mechanisms differ depending on whether the prevalent mortgage contract in the economy is a fixed or variable rate. In the variable-rate scenario, monetary policy is more stabilizing because there is a direct link between the policy rate and the borrowing rate. Nevertheless, this link is broken for the fixed-rate case. Therefore, an economy with variable rates will be more effective in minimizing the sticky price distortion, the one that affects savers. In the fixed-rate scenario, borrowing is more dependent on inflation and house prices. Although the policy rate does not affect the economy as much as in the variable-rate case, inflation affects real rates and therefore borrowing. The policy rate also has an effect on house prices, because as for any asset price, house prices move inversely with the interest rate, and thus also have an effect on credit. Then, borrowers may prefer fixed rates

\footnotetext{
${ }^{37}$ I define the optimal policy as the one that maximizes total welfare.
} 
because it creates a situation with higher inflation and this lowers real debt repayments, thus relaxing their collateral constraint. Borrowers prefer situations in which the central bank is not able to fight so effectively against inflation, that is, in the fixed-rate case. In this case, even though inflation can rise or decrease, it would be in general higher than in a situation in which the central bank has a more powerful monetary policy tool, that is, in the variable-rate case. This is why, borrowers prefer fixed-rate scenarios.

With respect to macroprudential policies, in the variable-rate case, the combination of monetary policy with an LTV rule would deliver more financial stability because, in a context of stable inflation, increasing LTVs in times of credit growth means containing credit. However, with fixed-rate mortgages, in which the real borrowing rate basically depends on inflation, higher inflation variability may offset the effects of increasing the LTV, and greater financial stability may not be achieved.

When the macroprudential policy is included in the Taylor rule, for the variable-rate case, as other studies that include credit variables in the monetary policy rule show, there may be little gain in terms of welfare. However, for the fixed-rate case, it creates a new mechanism. Making the nominal rate respond to an additional variable that is more volatile than inflation and output makes house prices react by more than with the simple Taylor rule. This increases financial stability through the effect of monetary policy on house prices.

\subsection{Welfare Measure}

As discussed in Benigno and Woodford (2008), the two approaches that have been used recently for welfare analysis in DSGE models include either characterizing the optimal Ramsey policy, or solving the model by using a second-order approximation to the structural equations for a given policy and then evaluating welfare using this solution. As in Mendicino and Pescatori (2007), I take this latter approach in order to be able to evaluate the welfare of the borrowers and savers separately and identify the trade-off that appears between them. ${ }^{38}$

The individual welfare for savers and the two types of borrowers respectively are defined as follows:

$$
\begin{aligned}
V_{u, t} & \equiv E_{t} \sum_{m=0}^{\infty} \beta^{m}\left(\ln C_{t+m}^{u}+j \ln H_{t+m}^{u}-\frac{\left(L_{t+m}^{u}\right)^{\eta}}{\eta}\right), \\
V_{c v, t} & \equiv E_{t} \sum_{m=0}^{\infty} \widetilde{\beta}^{m}\left(\ln C_{t+m}^{c v}+j \ln H_{t+m}^{c v}-\frac{\left(L_{t+m}^{c v}\right)^{\eta}}{\eta}\right),
\end{aligned}
$$

\footnotetext{
${ }^{38}$ See Monacelli (2006) for an example of the Ramsey approach in a model with heterogeneous consumers.
} 


$$
V_{c f, t} \equiv E_{t} \sum_{m=0}^{\infty} \widetilde{\beta}^{m}\left(\ln C_{t+m}^{c f}+j \ln H_{t+m}^{c f}-\frac{\left(L_{t+m}^{c f}\right)^{\eta}}{\eta}\right) .
$$

Following Mendicino and Pescatori (2007), I define social welfare as a weighted sum of individual welfare for the different types of households:

$$
V_{t}=(1-\beta) V_{u, t}+(1-\widetilde{\beta})\left[\alpha V_{c v, t}+(1-\alpha) V_{c f, t}\right]
$$

Borrowers' and savers' welfare are weighted by $(1-\widetilde{\beta})$ and $(1-\beta)$, respectively, so that the two groups receive the same level of utility from a constant consumption stream.

To make the results more intuitive, I present welfare changes in consumption equivalents, taking as a benchmark the situation in which there are no macroprudential policies. ${ }^{39}$

\subsection{Optimal Policy}

In this subsection, I study the mix of macroprudential and monetary policy that maximizes welfare. In particular, given a grid of possible parameters for the LTV and the Taylor rule (both the standard and the macroprudential ones), I perform a search that maximizes welfare, subject to the determinacy requirements. ${ }^{40}$ Parameters with a star correspond to the optimal ones, the ones that maximize welfare. I conduct the analysis first for the benchmark case, in which there are no macroprudential policies, so that I only optimize over the parameters of the standard Taylor rule. I find the parameters both for the variable- and the fixed-rate scenarios, as well as for an intermediate case in which the proportion of mortgages of each type is $50 \%$. The results are presented in Table 2.

\footnotetext{
${ }^{39}$ I follow Ascari and Ropele (2009).

${ }^{40}$ The Taylor principle also holds in the model with collateral constraints; for $\left(1+\phi_{\pi}\right) \leq 1$, there is indeterminacy.
} 
Table 2: Optimized Taylor rule (benchmark)

\begin{tabular}{cccc}
\hline \hline & Variable rate & $\alpha=\mathbf{0 . 5}$ & Fixed rate \\
$\left(1+\boldsymbol{\phi}_{\pi}^{*}\right)$ & 16 & 6.1 & 1.1 \\
$\boldsymbol{\phi}_{y}^{*}$ & 8.1 & 3.6 & 0 \\
\hline \hline Volatilities & & & \\
\hline \hline$\sigma_{\pi}$ & 0.25 & 0.29 & 0.52 \\
$\sigma_{y}$ & 2.12 & 2.10 & 2.10 \\
$\sigma_{b}$ & 1.90 & 17.53 & 27.32 \\
\hline \hline
\end{tabular}

The results in Table 2 represent the benchmark case, because they do not include macroprudential policies. We can see the difference in the optimality of monetary policy in both scenarios: fixed versus variable rates. For the variable-rate case, it is optimal for monetary policy to respond aggressively to both inflation and output. However, for fixed rates, because the link between the interest rate and the macroeconomic variables is weaker, it is not optimal for monetary policy to respond to any of the variables because in any case, the effect of nominal rates on the economy is very limited; real rates matter more strongly in this case, and they are driven by inflation. Furthermore, the nominal interest rate, in this case, also affects house prices and this also affects borrowing. In terms of stability, we see from the volatilities that a degree of greater stability, both macroeconomic and financial, is achieved with variable-rate mortgages. Macroeconomic stability is achieved because monetary policy is more effective with variable rates. ${ }^{41}$ With fixed rates, on the one hand, borrowers are more exposed to changes in house prices. On the other hand, because the nominal rate is fixed, the real rate depends mainly on inflation, and this one is more volatile than in the variable-rate case and real rates are more volatile. All this generates greater financial instability. The intermediate case lies in between the two extremes. We see that the optimal parameters do not imply a policy as aggressive as for the variable-rate case, but they are stronger than for the fixed one. In terms of inflation stability, the variable case is the one that delivers better results even though the variability of output is similar in all three cases. ${ }^{42}$ The variability

\footnotetext{
${ }^{41}$ See Rubio (2011) for a Taylor curve analysis that shows that monetary policy is more efficient with variable-rate mortgages and therefore the economy is always more stable under this scenario.

${ }^{42}$ In models with borrowers and savers, it is usually the case that when one considers two different scenarios, for aggregate output differences between them are not very large. By construction, trade-offs between borrowers and savers appear and they offset aggregate differences. On the other hand, as also pointed out in Rubio (2011), income effects on the labor supply decision are an important issue in these kinds of models and they compensate differences between settings. In this model, the labor supply decision depends on the level of consumption and in response to shocks, the labor supply moves both because of a substitution and an income effect and this latter one can partly offset aggregate differences. In fact, she experiments in her paper with GHH preferences, which have the property of shutting down the income effect on the labor supply decision, and finds larger differences between scenarios.
} 
of borrowing in the mixed case also lies in between the two polar cases.

Table 3: Optimized Taylor and LTV rule

\begin{tabular}{cccc}
\hline \hline & Variable rate & $\alpha=\mathbf{0 . 5}$ & Fixed rate \\
Taylor rule & & & \\
$\left(1+\boldsymbol{\phi}_{\pi}^{*}\right)$ & 1.9 & 1.1 & 1.1 \\
\hline $\boldsymbol{\phi}_{y}^{*}$ & 0.5 & 0.1 & 0 \\
\hline LTV rule & & & \\
$\boldsymbol{\phi}_{b}^{k *}$ & 0.8 & 0.1 & 0.01 \\
\hline \hline Welfare gain & & & \\
\hline \hline Savers & -0.40 & -0.99 & -0.98 \\
Borrowers & 0.68 & 1.43 & 5.09 \\
Total & 0.005 & -0.005 & -0.89 \\
\hline \hline Volatilities & & & \\
\hline \hline & & & \\
$\sigma_{\pi}$ & 0.28 & 0.48 & 0.55 \\
$\sigma_{y}$ & 2.10 & 2.09 & 2.10 \\
$\sigma_{b}$ & 1.27 & 10.99 & 27.35 \\
\hline \hline
\end{tabular}

In Table 3, I present the optimized monetary policy when it interacts with an LTV rule. We see that, in this case, for the variable-rate scenario, the optimal response for monetary policy is substantially less aggressive than in the benchmark case without macroprudential policies in place. The macroprudential LTV rule complements the role of monetary policy, ${ }^{43}$ and both interacting together manage to achieve a more stable macroeconomic and financial scenario. However, this is at the expense of a slightly greater inflation volatility. ${ }^{44}$ The increase in inflation volatility makes savers worse off because they care about the sticky-price friction. On the contrary, borrowers are better off for two reasons; they like higher inflation because they have to repay their debt, and they prefer a more stable financial scenario, because this helps them smooth their consumption. ${ }^{45}$

\footnotetext{
${ }^{43}$ The sense in which macroprudential policy is complementary to monetary policy is that a similar level of inflation volatility is achieved with considerably less aggressive monetary policy. In addition, the volatility of debt is substantially reduced.

${ }^{44}$ This is a typical result found in the literature. The results are in line, for example, with Gelain et al. (2013) who show that while macroprudential policies can stabilize some variables, they can magnify the volatility of others, especially inflation.

${ }^{45}$ Welfare changes are presented in consumption equivalents, taking as benchmark a situation with no macroprudential policies. Therefore, a positive value means a welfare gain, that is, the percentage of consumption that the consumer would
} 
For the intermediate and the fixed-rate case, the optimal reaction of both monetary and macroprudential policies is smaller then that in the variable-rate scenario. Monetary policy is still not effective, and therefore the optimal response is minimal, as in the benchmark case. The introduction of the LTV rule has similar effects to those in the variable-rate scenario. It does not worsen the volatility of output but it increases the volatility of inflation. As remarked by Lustig (2006) and Rubio (2011), the inflation channel that relaxes borrowing constraints should be much more effective when fixed-rate mortgages are predominant, because agents care about real rates. Therefore, agents are more sensitive to changes in inflation in a fixed-rate scenario. This is the reason why borrowers' welfare gains and savers' losses are larger in this case, even though in the aggregate, losses outweigh gains. However, in the fixed-rate case, welfare gains come mainly from the fact that inflation is more volatile, but not from the financial side. Given that inflation is less stable, borrowers benefit in terms of debt repayments, relaxing their constraint. This offsets the constraint tightening that the LTV rule should impose. As a result, although the economy is better off, greater financial stability is not achieved. In the intermediate case, there is some gain in terms of financial stability though.

Table 4: Optimized macroprudential Taylor rule

\begin{tabular}{cccc}
\hline & Variable rate & $\alpha=\mathbf{0 . 5}$ & Fixed rate \\
$\left(1+\phi_{\pi}^{*}\right)$ & 13.1 & 1.1 & 1.1 \\
$\boldsymbol{\phi}_{y}^{*}$ & 6 & 0.1 & 0 \\
$\boldsymbol{\phi}_{b}^{*}$ & 0.9 & 0.1 & 0.01 \\
\hline \hline Welfare gain & & & \\
\hline \hline Savers & 0.09 & -0.99 & -0.99 \\
Borrowers & -0.09 & 1.94 & 4.47 \\
Total & -0.007 & 0.30 & 1.77 \\
\hline \hline Volatilities & & & \\
\hline \hline & & & \\
$\sigma_{\pi}$ & 0.24 & 0.63 & 0.54 \\
$\sigma_{y}$ & 2.12 & 2.11 & 2.11 \\
$\sigma_{b}$ & 1.93 & 19.73 & 20.57 \\
\hline \hline
\end{tabular}

In Table 4, the macroprudential policy is introduced directly in the Taylor rule, by letting the interest rate respond to credit growth. The results show that, although it is optimal to respond to credit growth, be willing to pay in order to be in a better situation. 
the optimal monetary policy is aggressive, as in the case in which the central bank only responds to inflation and output. As is common in the literature, for the standard variable-rate case, there are no welfare gains from responding to credit variables. ${ }^{46}$ Table 4 shows that inflation volatility is slightly lower than in the benchmark case and financial instability slightly larger. Thus, with this new optimized Taylor rule, borrowers are slightly worse off with respect to the case in which credit variables are not included in the rule because inflation is less volatile, although there are no benefits from the financial side. This is offset by the fact that savers live in a slightly more stable world.

However, for the intermediate and the fixed-rate cases, the gains are larger, coming mainly from the borrowers' side. When the nominal rate responds to credit growth, it reacts more strongly to changes in the economy. Even though the optimal response is small, credit is a volatile variable and thus the interest rate responds more strongly than with the standard Taylor rule. This has an effect on house prices and the collateral constraint is affected through this channel. For example, if there is an increase in credit, the interest rate will increase and this will decrease house prices. The fall in house prices tightens the collateral constraint and helps achieve greater financial stability. A scenario with greater financial stability is beneficial for borrowers. This is an example of a theory of second best, given the distortion that the collateral constraint is introducing.

\subsection{Impulse Responses}

Figure 2 presents the impulse responses to a technology shock for a variable-rate economy and for the optimized parameters found in Tables $2-4 .{ }^{47}$ The technology shock increases output and decreases inflation. As a result, the interest rate increases slightly, to respond to the increase in output, especially in the case in which the interest rate responds to credit growth. For the case in which the macroprudential policy is represented by an LTV rule, the interest rate decreases because the optimal reaction parameters in the Taylor rule are much smaller than in the other two cases. It also reflects that relatively more weight is placed on inflation relative to output in this instance. The borrowing interest rate in this case varies one-for-one with the policy rate. House prices move as a mirror image of the interest rate and also respond to the increase in housing demand derived from better economic conditions. As house prices increase, borrowing increases. However, the increase in borrowing is softer in the case in which

\footnotetext{
${ }^{46}$ See, for instance, Iacoviello (2005), who shows with a policy frontier analysis that little is gained in terms of inflation and output stabilization by responding to asset prices. Christiano et al. (2014) also find that consumption falls after a rise in risk.

${ }^{47}$ The Appendix contains extra graphs with impulse responses for the other shocks of the model. Impulse responses for the intermediate case in which $\alpha=0.5$ are available upon request.
} 

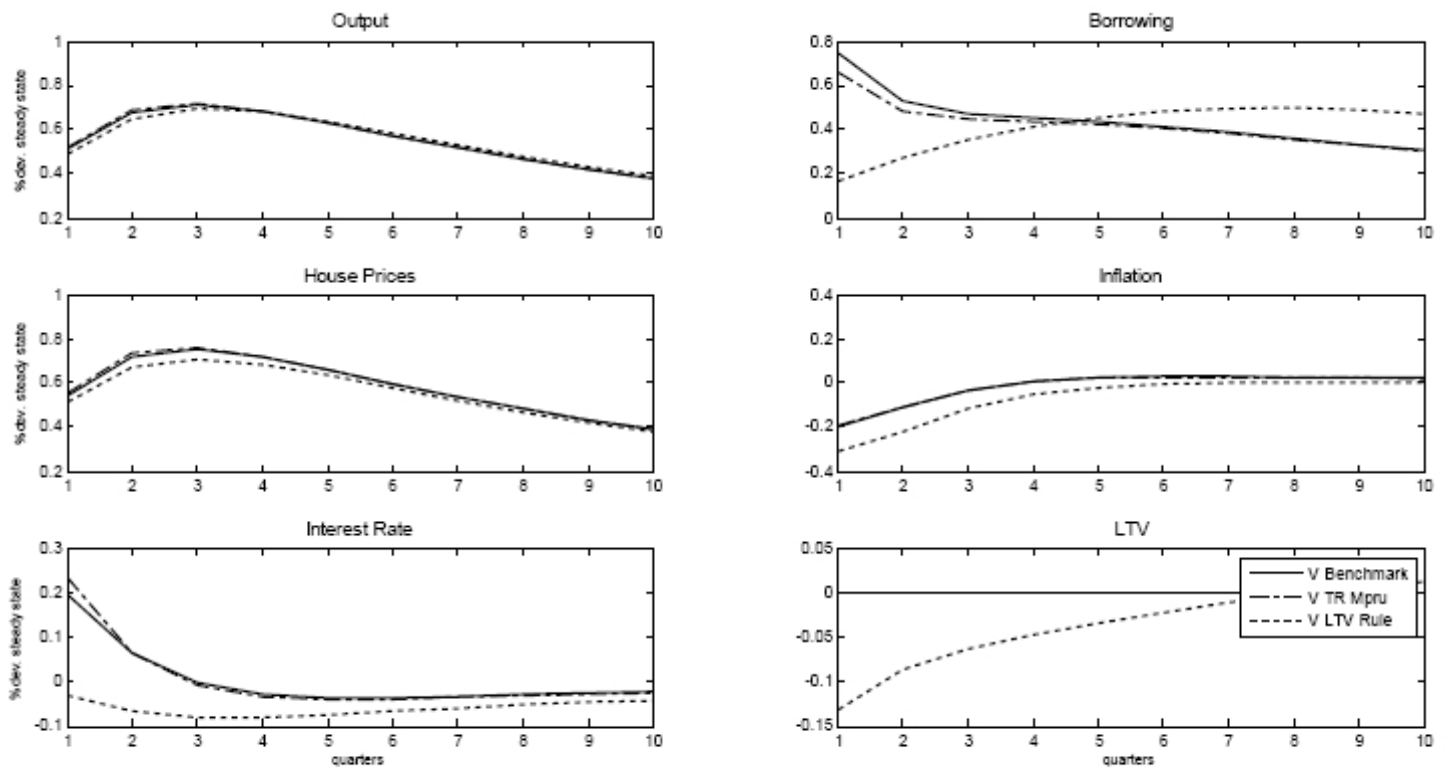

Figure 2: Impulse responses to a technology shock: variable rate.

macroprudential policies are present. When the macroprudential policy is incorporated in the Taylor rule, the increase in the interest rate is larger and then, borrowing increases by less on impact, although the effect dissipates in subsequent periods. However, borrowing is really contained when the LTV rule is active. In this case, as a reaction to credit growth, the macroprudential regulator cuts the LTV, making credit less accessible for borrowers. For this latter case, the macroprudential measure mitigates the effect of the technology shock.

Figure 3 displays the impulse responses to a technology shock for the fixed-rate economy, for its optimized policy parameters. It is also the case that the shock causes output to increase and inflation to decrease. Optimal reaction parameters in the Taylor rule for the fixed-rate case make the policy rate (plotted in the lower left panel) respond only to inflation, and in a not too aggressive matter. Therefore, because inflation decreases, nominal interest rates also decrease for the three cases, with the fall being more persistent when interest rates also react to credit growth. However, given that the link between the policy rate and the borrowing rate is weaker with fixed rates, the real rate, that is negative inflation, is what matters for borrowers. The decrease in inflation makes the real rate increase and therefore borrowing decreases. Although house prices increase, this does not offset the increase in the real interest rate. Furthermore, the increase in house prices is smaller in the case of credit growth being incorporated into the Taylor rule, creating an extra channel to decrease credit further. As a result, in 

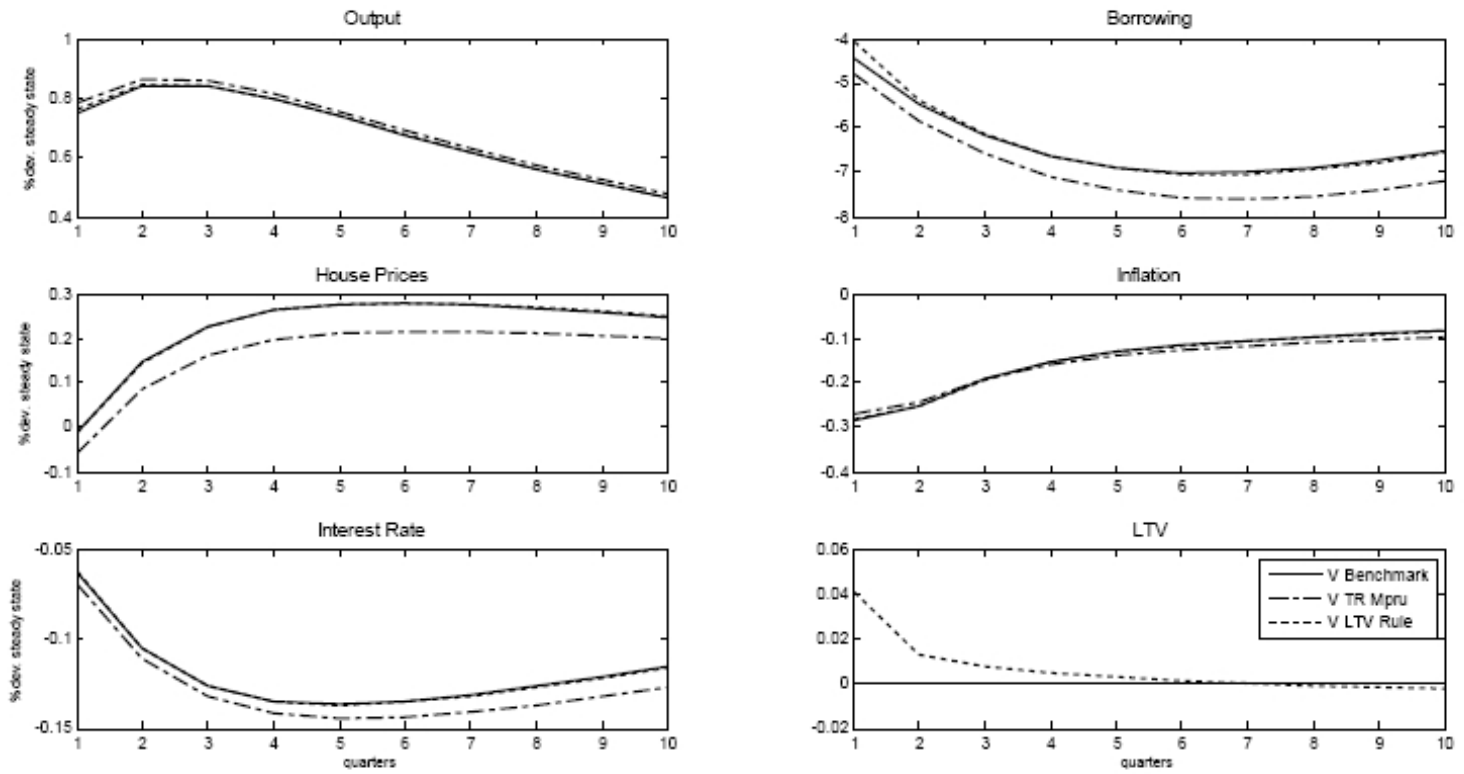

Figure 3: Impulse responses to a technology shock: fixed rate.

this case, borrowers devote less income to purchasing houses and purchase more consumption goods, making output increase by more in this scenario. The decrease in credit makes the LTV increase, when the LTV rule is active and, on impact, credit does not decrease as much, although the effect diminishes very quickly. Thus, while real rates decrease in the variable-rate scenario, they increase in the fixed-rate one, making borrowing and LTVs (for the LTV rule case) move in opposite directions.

For the sake of completeness, I have also presented in the Appendix impulse responses for an expansionary monetary policy shock and for a house price shock and a demand shock (Figures A1-A6), both for the variable and fixed-rate scenarios. Responses to house price shocks are also worth it to be discussed, since moderation of house prices is something relevant for macroprudential policy. For the variable-rate case, house prices increase for the benchmark and for the scenarios with macroprudential policies. However, with the LTV rule, the increase is more mitigated because the LTV is cut. This makes borrowing not to increase as much because of the wealth effect as in the benchmark case. With the macroprudential Taylor rule, the interest rate increases by more than in the other cases and this also makes borrowing not to increase as much as in the benchmark and makes output decrease. With fixed rates there is less difference between the benchmark and the case in which the macroprudential policy is introduced. With the LTV rule also borrowing is mitigated with respect to the benchmark but by less than in the variable-rate scenario. The response of the macroprudential Taylor rule does not cause 
much difference in this case with respect to the benchmark.

\section{Conclusions}

In this paper, I studied the ability of monetary policy to affect financial markets under both fixed- and variable-rate mortgages. I have developed a new Keynesian general equilibrium model with housing and collateral constraints to analyze the combined effects of macroprudential and monetary policies with these two types of mortgage contracts. There are unconstrained and constrained individuals who correspond to the savers and borrowers of the economy. I explicitly introduced fixed- and variable-rate mortgages, that is, constrained individuals are of two types: those who borrow at a variable rate and those who borrow at a fixed rate.

First, in order to gain some insight, I studied the dynamics of the model for the case in which there are no macroprudential policies. The results show that having variable- or fixed-rate mortgages not only affects the macroeconomy but also the financial side of the economy. Therefore, the structure of mortgage contracts has clear implications, not only for monetary policy reaction and for macro variables, but also for the implementation of macroprudential policies.

I proposed two types of macroprudential policies. The first one is a simple rule on the LTV. In this case, the LTV would be the instrument of the macroprudential regulator, responding to credit growth. The second one is a Taylor rule for the interest rate, in which rates would respond not only to inflation and output but also to credit growth. In this second case, both monetary and macroprudential policies would be implemented with a single instrument; the interest rate.

From a normative perspective, I analyzed how the optimality of monetary and macroprudential policies changes when rates in the economy are either variable or fixed. First, I performed the analysis for the benchmark case, the one that does not include macroprudential policies. For the variable-rate scenario, it is optimal for monetary policy to respond aggressively against both inflation and output. However, for fixed rates, because the link between the interest rate and the macroeconomic variables is weaker, it is not optimal for monetary policy to respond strongly to any of the variables. Greater stability, both macroeconomic and financial, is achieved with variable-rate mortgages. Second, I studied the optimality of monetary policy interacting with the LTV rule. For variable rates, the optimal response for monetary policy is substantially less aggressive. The macroprudential LTV rule complements the role of monetary policy and interacting both together achieves a more stable macroeconomic and financial 
environment. For the fixed-rate case, the optimal reaction of both monetary and macroprudential policies is smaller than that in the variable-rate scenario. Welfare gains, however, come mainly from the fact that inflation is more volatile but not from the financial side. Finally, I studied the welfare and optimality implications of including credit growth directly in the Taylor rule for the interest rate. For the standard variable-rate case, the welfare gains of responding to credit variables are very small. Albeit, for the fixed-rate case gains are larger, coming mainly from the borrowers' side because this delivers greater financial stability.

In conclusion, macroprudential policies are welfare enhancing regardless of the mortgage structure prevalent in the economy. Nevertheless, when mortgages are variable rate, an LTV rule combined with monetary policy is preferable to including credit variables in the interest-rate rule. When rates are fixed, using the interest rate as an instrument, to stabilize both the macroeconomy and financial markets, delivers higher welfare and stability than having two separate instruments. Thus, interestingly, with fixed rates, even though monetary policy is less effective in stabilizing the macroeconomy, it seems a good tool with which to stabilize financial markets. 


\section{References}

[1] Alpanda, S., Zubairy, S., (2014), Addressing Household Indebtedness: Monetary, Fiscal or Macroprudential Policy?, Staff Working Papers 14-58, Bank of Canada

[2] Andrés, J., Arce, O., Thomas, C., (2009), Banking Competition, Collateral Constraints and Optimal Monetary Policy, mimeo

[3] Angelini, P., Neri, S., Panetta, F., (2014), "The Interaction between Capital Requirements and Monetary Policy," Journal of Money, Credit and Banking, Volume 46, Issue 6, pp. 1073-1112

[4] Aoki, K., Proudman, J., Vlieghe, G., (2004), "House Prices, Consumption, and Monetary Policy: A Financial Accelerator Approach," Journal of Financial Intermediation, 13 (4), 414-435

[5] Assenmacher-Wesche K., Gerlach, S., (2008), Ensuring Financial Stability: Financial Structure and the Impact of Monetary Policy on Asset Prices, Institute for Empirical Research in Economics, University of Zurich, Working Paper 361

[6] Basel Committee on Banking Supervision, (2010), "Guidance for national authorities operating the countercyclical capital buffer," Bank for International Settlement publication

[7] Benigno, P., Woodford, M., (2008), Linear-Quadratic Approximation of Optimal Policy Problems, mimeo

[8] Brzoza-Brzezina, M., Gelain, P., Kolasa, M., (2014), Monetary and macroprudential policy with multiperiod loans, NBP Working Paper No. 192

[9] Calza, A., Monacelli, T., Stracca, L., (2013), "Housing Finance and Monetary Policy," Journal of the European Economic Association

[10] Calvo, G., (1983), "Staggered Prices in a Utility-Maximizing Framework," Journal of Monetary Economics, 12 (3), 383-398

[11] Campbell J., Cocco, J., (2003), "Household Risk Management and Optimal Mortgage Choice," Quarterly Journal of Economics, 118 (4), 1449-1494

[12] Christiano, L., Motto, R., Rostagno, M., (2014), "Risk Shocks," American Economic Review, 104 (1), 27-45

[13] Clarida, Galí, Gertler, (2000), "Monetary Policy Rules and Macroeconomic Stability: Evidence and Some Theory," Quarterly Journal of Economics, 115, 147-180

[14] Davis, M., Heathcote, J., (2005), "Housing and the Business Cycle," International Economic Review, $46(3), 751-784$

[15] Debelle, G., (2004), "Household Debt and the Macroeconomy," BIS Quarterly Review

[16] Domeij, D., Flodén, M., (2006), "The Labor-Supply Elasticity and Borrowing Constraints: Why Estimates are Biased," Review of Economic Dynamics, 9, 242-262 
[17] EMF, (2006), "Study on Interest Rate Variability in Europe," EMF Publication

[18] Faia, E., Monacelli, T., (2007), "Optimal Interest Rate Rules, Asset Prices, and Credit Frictions," Journal of Economic Dynamics and Control, 31, 3228-3254

[19] Fuhrer, J., Moore, G., (1995), "Inflation Persistence," Quarterly Journal of Economics, February 1995, 110 (1), pp. 303-36.

[20] Garriga, C., Kydland, F., Sustek, R., (2015). "Mortgages and Monetary Policy," Working Papers 2015-33, Federal Reserve Bank of St. Louis.

[21] Gelain, P., Lansing, K., Mendicino, C., (2013), "House Prices, Credit Growth, and Excess Volatility: Implications for Monetary and Macroprudential Policy," International Journal of Central Banking, $9(2)$

[22] Graham, L., Wright, S., (2007), "Nominal Debt Dynamics, Credit Constraints and Monetary Policy," The B.E. Journal of Macroeconomics, 7 (1)

[23] Iacoviello, M., (2005), "House Prices, Borrowing Constraints and Monetary Policy in the Business Cycle," American Economic Review, 95 (3), 739-764

[24] Iacoviello, M., Neri, S., (2008), Housing Market Spillovers: Evidence from an Estimated DSGE Model, mimeo

[25] Kannan, P., Rabanal, P., Scott, A., (2012), "Monetary and Macroprudential Policy Rules in a Model with House Price Booms," The B.E. Journal of Macroeconomics, Contributions, 12 (1)

[26] Krusell, P., Smith, A., (1998), "Income and Wealth Heterogeneity in the Macroeconomy," The Journal of Political Economy, 106 (5), 867-896

[27] Lawrance, E., (1991), "Poverty and the Rate of Time Preference: Evidence from Panel Data," The Journal of Political Economy, 99 (1), 54-77

[28] Lustig, H., (2006), Comment on "Optimal Monetary Policy with Collateralized Household Debt and Borrowing Constraints," in conference proceedings "Monetary Policy and Asset Prices" edited by J. Campbell.

[29] Mendicino, C., Pescatori, A., (2007), Credit Frictions, Housing Prices and Optimal Monetary Policy Rules, mimeo

[30] McCallum, B., (2001), "Should Monetary Policy Respond Strongly To Output Gaps?," American Economic Review, 2001, 91(2), 258-262

[31] Monacelli, T., (2006), "Optimal Monetary Policy with Collateralized Household Debt and Borrowing Constraints," in conference proceedings "Monetary Policy and Asset Prices" edited by J. Campbell.

[32] Rabanal, P., (2004), Monetary Policy Rules and the U.S. Business Cycle: Evidence and Implications, IMF Working Paper WP/04/164 
[33] Rubio, M., (2011), "Fixed- and Variable-Rate Mortgages, Business Cycles, and Monetary Policy," Journal of Money, Credit and Banking, 43 (4), 657-688

[34] Rubio, M., Carrasco-Gallego, J.A., (2014), "Macroprudential and Monetary Policies: Implications for Financial Stability and Welfare," Journal of Banking and Finance

[35] Rubio, M., Carrasco-Gallego, J.A., (2015), "Macroprudential and Monetary Policy Rules: A Welfare Analysis," The Manchester School

[36] Shea, P., (2008), Interest Rate Rules, Learning, and Credit Constrained Housing Markets, mimeo

[37] Smets, F., Wouters F., (2002), An Estimated Stochastic General Economic Model of the Euro Area, ECB WP 171

[38] Yun, T., (1996), "Nominal Price Rigidity, Money Supply Endogeneity and Business Cycles," Journal of Monetary Economics, 37, 175-391 


\section{Appendix}

Tables and Figures

\begin{tabular}{|c|c|c|c|}
\hline \multicolumn{4}{|c|}{ Table A1: Predominant Type of Mortgage Interest Rate } \\
\hline \hline Australia & Variable & Italy & Mixed \\
\hline Austria & Fixed & Japan & Mixed \\
\hline France & Fixed & Spain & Variable \\
\hline Germany & Fixed & United Kingdom & Variable \\
\hline Greece & Variable & United States & Fixed \\
\hline
\end{tabular}

Source: ECB (2003), IMF

Table A2: Sensitivity Analysis to different values of $\beta$

\begin{tabular}{ccccc|cccc}
\hline & \multicolumn{3}{c|}{ Variable rate } & \multicolumn{5}{c}{ Fixed rate } \\
\hline \hline$\beta$ & $\mathbf{0 . 9 5}$ & $\mathbf{0 . 9 6}$ & $\mathbf{0 . 9 7}$ & $\mathbf{0 . 9 8}$ & $\mathbf{0 . 9 5}$ & $\mathbf{0 . 9 6}$ & $\mathbf{0 . 9 7}$ & $\mathbf{0 . 9 8}$ \\
\hline \hline Volatilities & & & & & & & & \\
\hline \hline$\sigma_{\pi}$ & 0.27 & 0.27 & 0.26 & 0.26 & 0.22 & 0.21 & 0.21 & 0.20 \\
$\sigma_{y}$ & 2.25 & 2.25 & 2.24 & 2.24 & 2.37 & 2.36 & 2.35 & 2.33 \\
$\sigma_{b}$ & 5.41 & 5.55 & 5.71 & 5.87 & 11.75 & 12.04 & 12.34 & 12.63 \\
\hline \hline
\end{tabular}

Table A3: Sensitivity Analysis to different values of $\gamma$

\begin{tabular}{ccccc|cccc}
\hline \multicolumn{1}{c}{} & \multicolumn{3}{c|}{ Variable rate } & \multicolumn{5}{c}{ Fixed rate } \\
\hline \hline$\gamma$ & $\mathbf{0 . 2}$ & $\mathbf{0 . 5}$ & $\mathbf{0 . 6 4}$ & $\mathbf{0 . 9}$ & $\mathbf{0 . 2}$ & $\mathbf{0 . 5}$ & $\mathbf{0 . 6 4}$ & $\mathbf{0 . 9}$ \\
\hline \hline Volatilities & & & & & & & & \\
\hline \hline$\sigma_{\pi}$ & 0.27 & 0.21 & 0.26 & 0.33 & 0.35 & 0.18 & 0.20 & 0.29 \\
$\sigma_{y}$ & 2.56 & 2.29 & 2.24 & 2.19 & 2.41 & 2.33 & 2.33 & 2.26 \\
$\sigma_{b}$ & 5.19 & 5.78 & 5.87 & 5.97 & 14.43 & 10.58 & 12.63 & 17.87 \\
\hline \hline
\end{tabular}



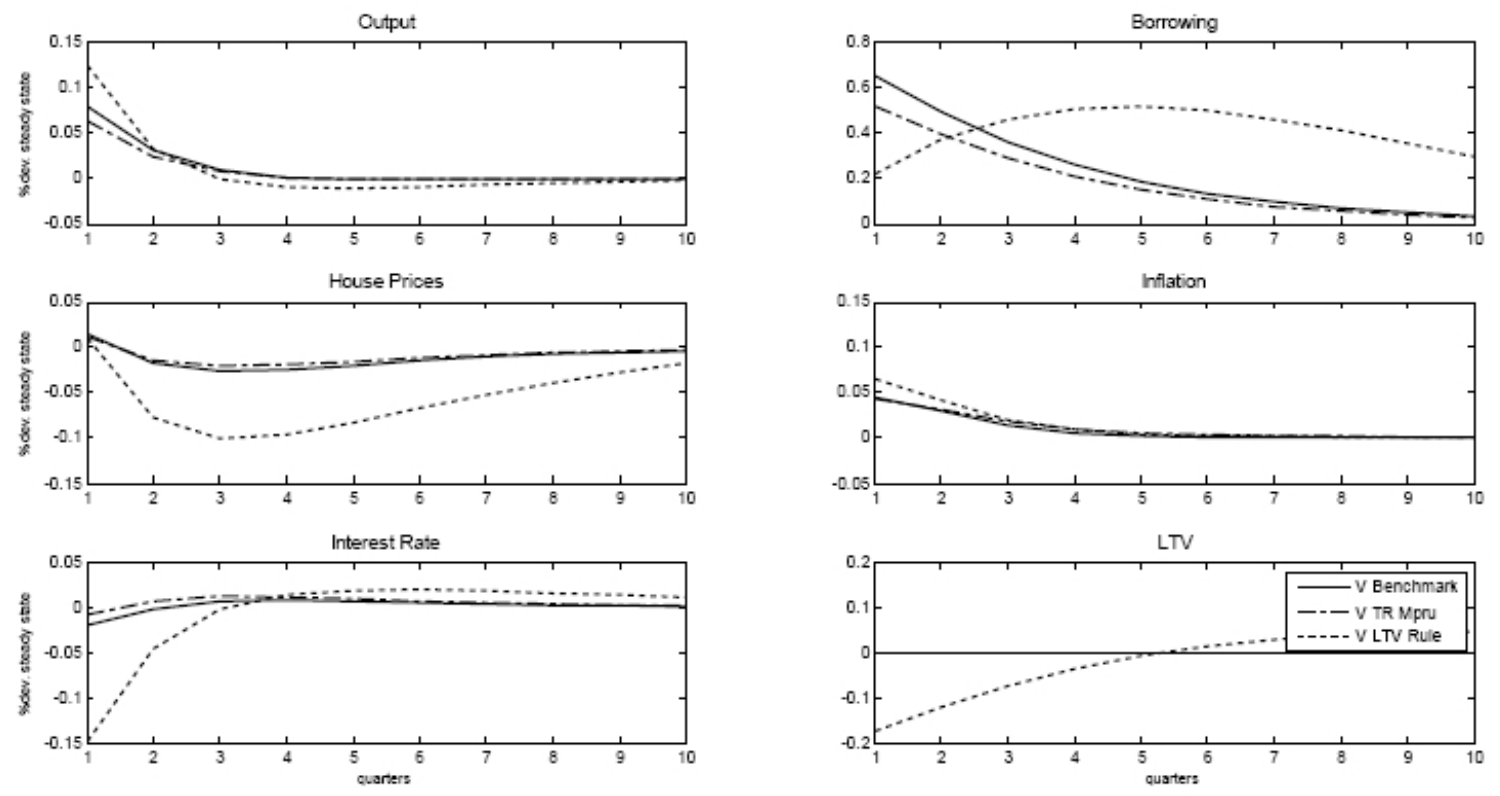

Figure A1: Impulse Responses to an Expansionary Monetary Policy Shock. Variable Rates.
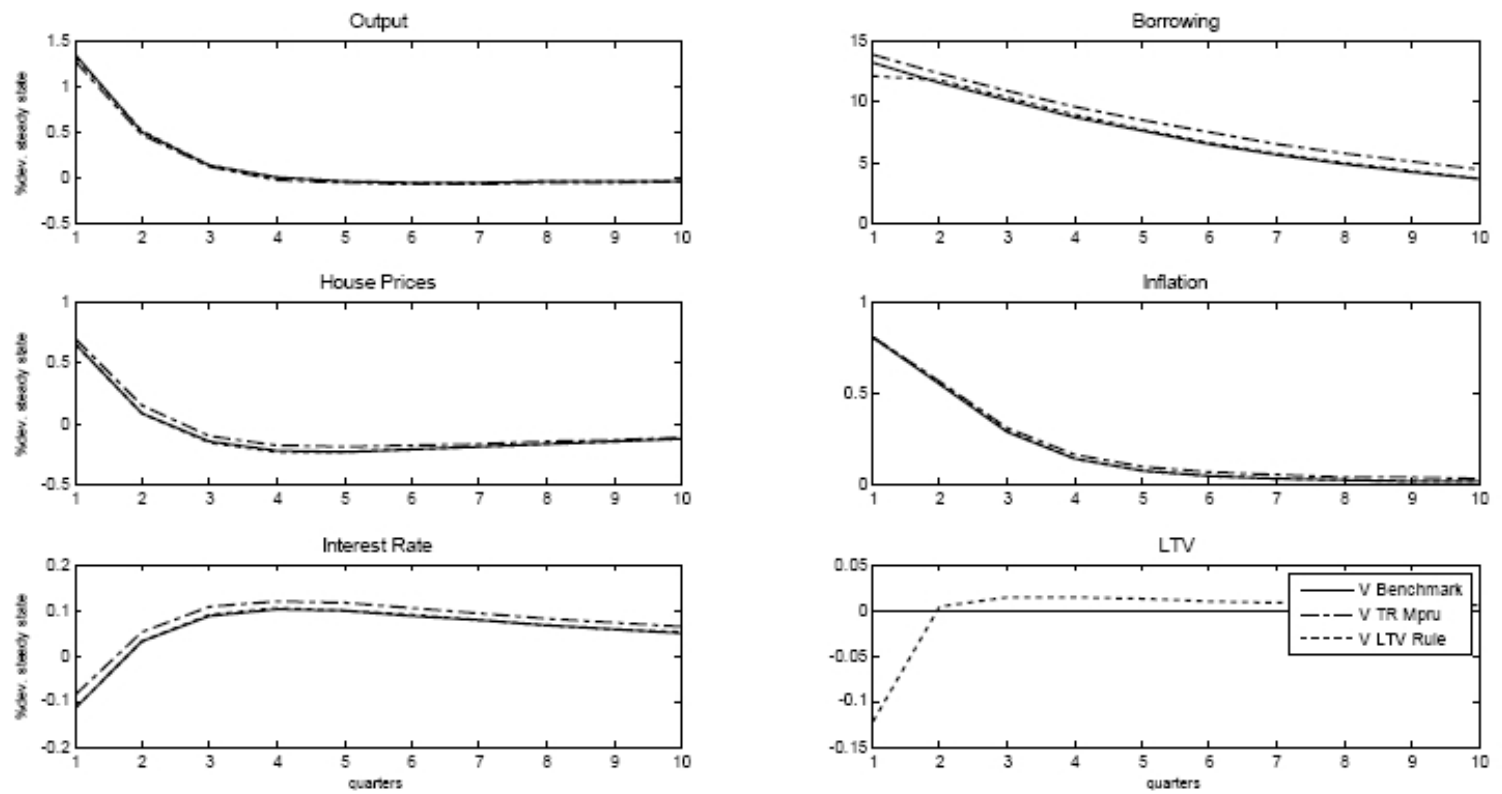

Figure A2: Impulse Responses to an Expansionary Monetary Policy Shock. Fixed Rates. 

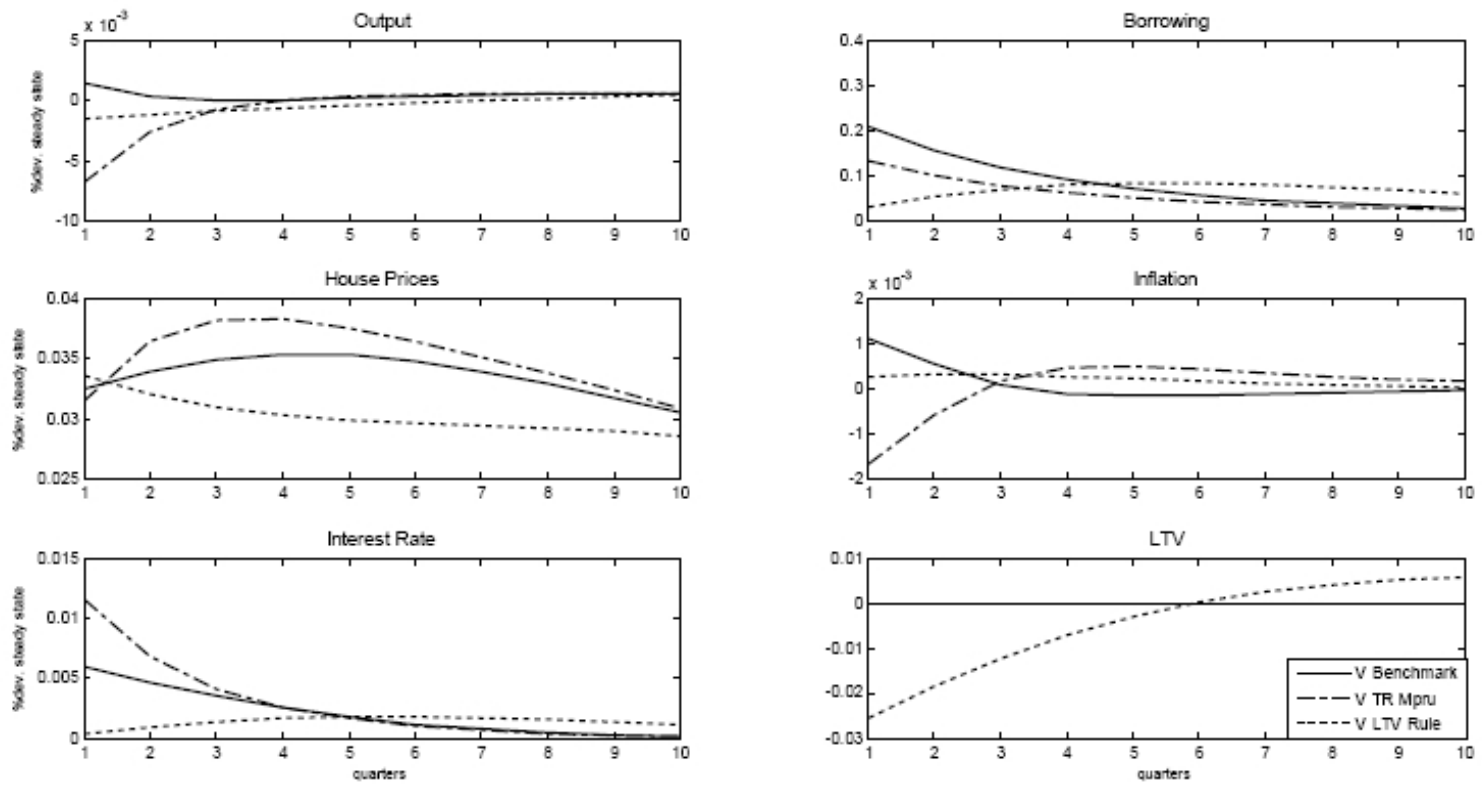

Figure A3: Impulse Responses to a House Price Shock. Variable Rates.
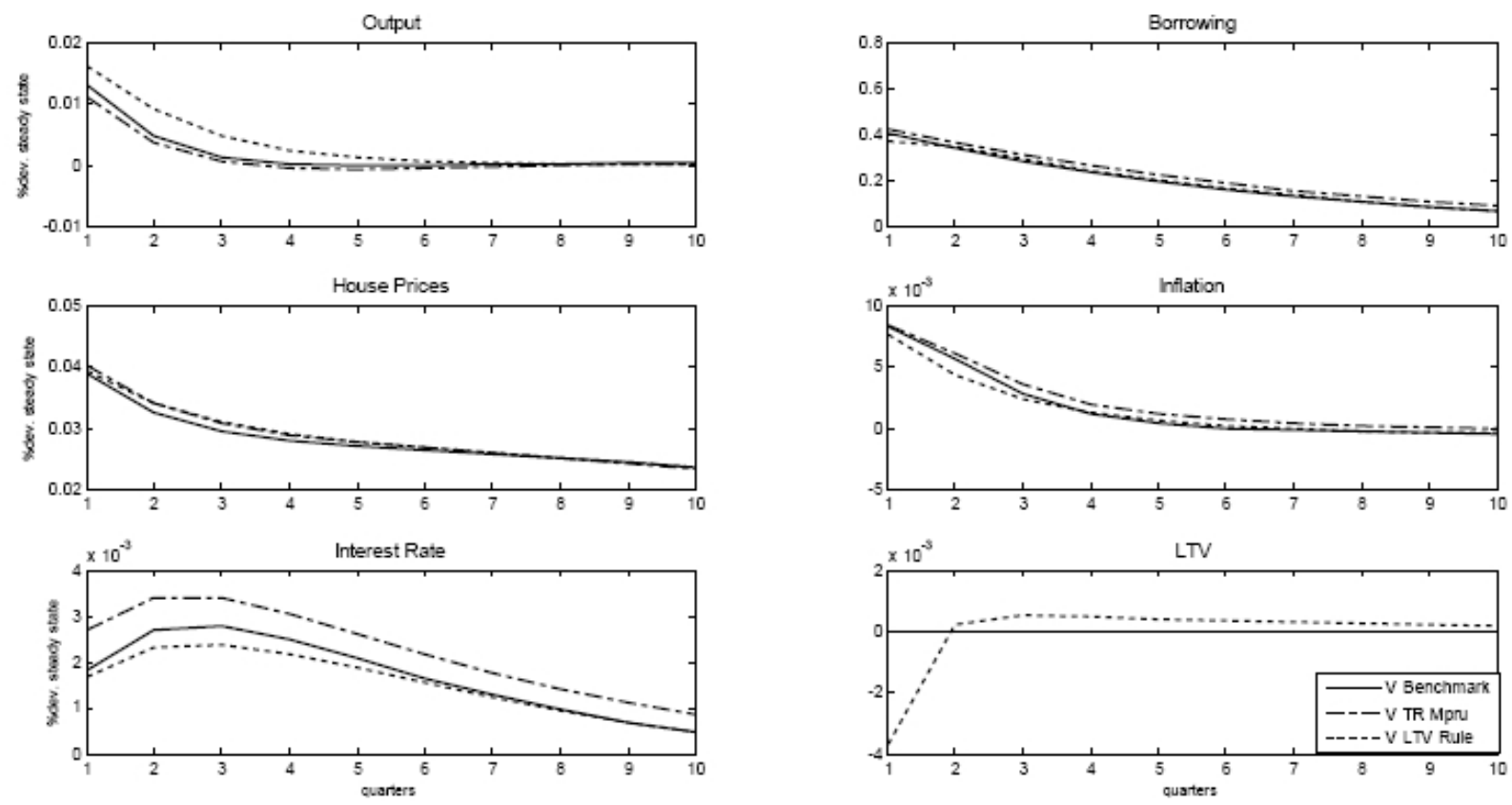

Figure A4: Impulse Responses to a House Price Shock. Fixed Rates. 

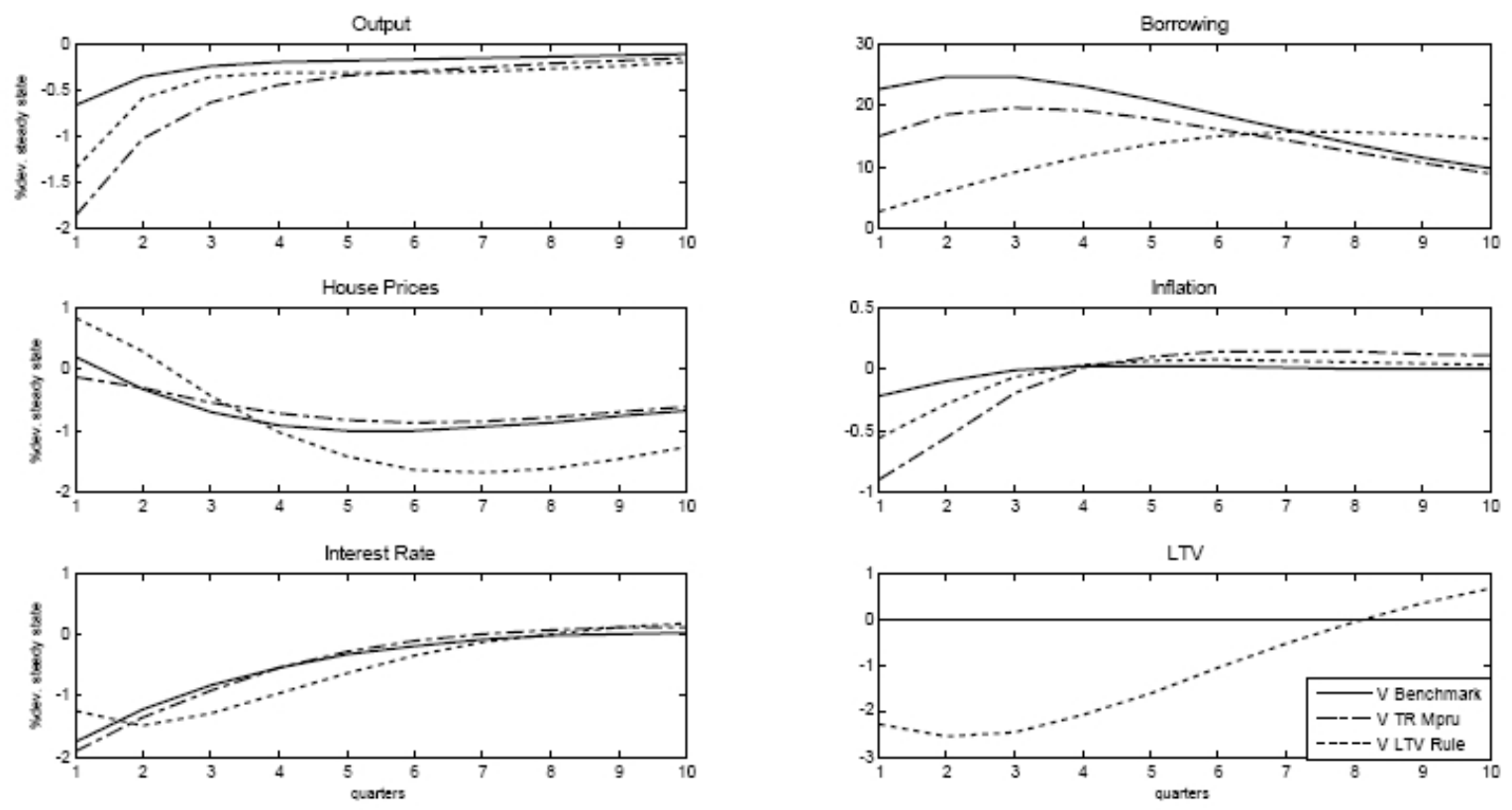

Figure A5: Impulse Responses to a Demand Shock. Variable Rates.
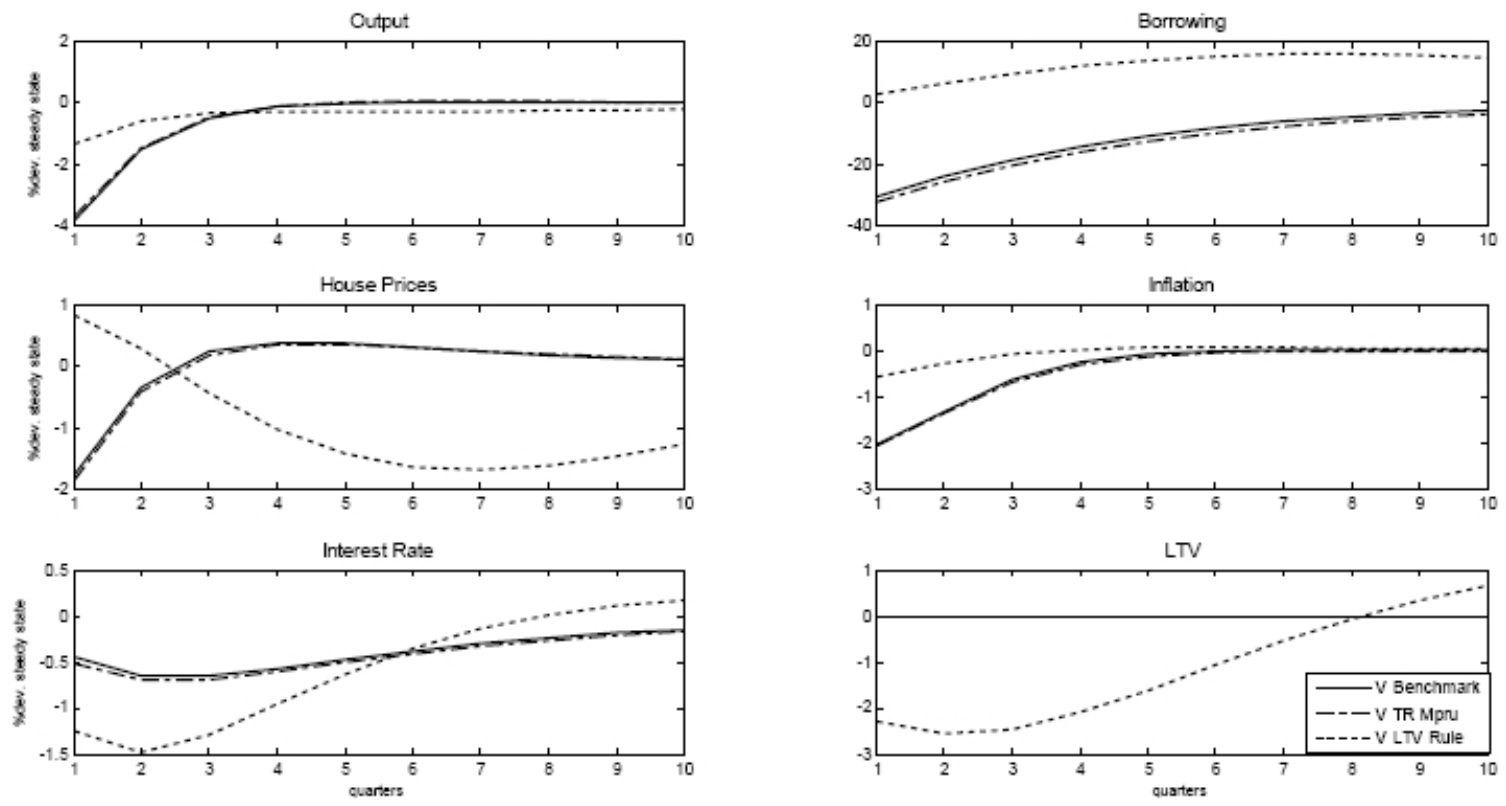

Figure A6: Impulse Responses to a Demand Shock. Fixed Rates. 


\section{Model Derivations}

\section{Steady-State Relationships}

Using (9) in the steady state we obtain $R=1 / \beta$. From (5) and (6) we have that $\bar{R}^{*}=\bar{R}=R=1 / \beta$.

From the first order conditions for housing we can obtain the steady-state consumption-to-housing ratio for both constrained and unconstrained consumers:

$$
\begin{gathered}
\frac{C^{u}}{q H^{u}}=\frac{1}{j}(1-\beta), \\
\frac{C^{c}}{q H^{c}}=\frac{1}{j}\left(1-\widetilde{\beta}-k_{S S}(\beta-\widetilde{\beta})\right)=\frac{1}{j} \Phi,
\end{gathered}
$$

where $\Phi \equiv\left(1-\widetilde{\beta}-k_{S S}(\beta-\widetilde{\beta})\right)$. From (19) and (27)we obtain the constrained and unconstrained consumption-to-output ratio in the steady state:

$$
\begin{gathered}
\frac{C^{c}}{Y}=\frac{1-\gamma}{X}\left(\frac{\Phi}{\Phi+j k_{S S}(1-\beta)}\right), \\
\frac{C^{u}}{Y}=1-\frac{C^{c}}{Y},
\end{gathered}
$$

where $X=\varepsilon /(\varepsilon-1)$

The housing-to-output ratio for constrained and unconstrained consumers:

$$
\begin{gathered}
\frac{q H^{c}}{Y}=\frac{(1-\gamma) j}{X}\left(\frac{1}{\Phi+j k_{S S}(1-\beta)}\right), \\
\frac{q H^{u}}{Y}=\frac{X j\left(\Phi+j k_{S S}(1-\beta)\right)-j(1-\gamma) \Phi}{X\left(\Phi+j k_{S S}(1-\beta)\right)(1-\beta)} .
\end{gathered}
$$

\section{Log-Linearized Model}

The model can be reduced to the following linearized system in which all lower-case variables with a hat denote percent changes from the steady state and steady-state levels are denoted by dropping the time index: 
Financial intermediary

$$
\begin{gathered}
\widehat{\bar{r}}_{\tau}^{*}=\frac{(1-\beta)}{\beta} E_{\tau} \sum_{i=\tau+1}^{\infty} \beta^{i-\tau} \widehat{r}_{i-1}, \\
\widehat{\bar{r}}_{t}=\widehat{\bar{r}}_{t-1} \Rightarrow \widehat{\bar{r}}_{t}=\widehat{\bar{r}}=0 .
\end{gathered}
$$

Equation (43) is the log-linearized fixed interest rate in each period $\tau$. Using this result we can obtain the log-linearized aggregate fixed interest rate, which is zero in deviations from the steady state (equation (44)), given the initial condition of being at the steady state in the absence of shocks.

\section{Aggregate Demand}

$$
\begin{gathered}
\widehat{y}_{t}=\frac{C^{u}}{Y} \widehat{c}_{t}^{u}+\frac{C^{c}}{Y} \widehat{c}_{t}^{c}, \\
\widehat{c}_{t}^{u}=E_{t} \widehat{c}_{t+1}^{u}-\left(\widehat{r}_{t}-E_{t} \widehat{\pi}_{t+1}\right)+v_{t}, \\
\widehat{c}_{t}^{c}=\left(\frac{\Phi+j k_{S S}(1-\beta)}{\Phi}\right)\left(\widehat{y}_{t}-\widehat{x}_{t}\right)-\frac{j}{\Phi}\left(\widehat{h}_{t}^{c}-\widehat{h}_{t-1}^{c}\right) \\
+\frac{k_{S S} j}{\Phi}\left(\beta \widehat{b}_{t}^{c}-\widehat{b}_{t-1}^{c}\right)-k_{S S} j\left(\alpha \widehat{r}_{t-1}-\widehat{\pi}_{t}\right)+v_{t}, \\
\widehat{b}_{t}^{c}=\widehat{k}_{t}+E_{t} \widehat{q}_{t+1}+\widehat{h}_{t}^{c}-\left(\alpha \widehat{r}_{t}-E_{t} \widehat{\pi}_{t+1}\right) .
\end{gathered}
$$

Equation (45) is the log-linearized goods market clearing condition. Equation (46) is the Euler equation for unconstrained consumption. Equation (47) is the budget constraint for constrained individuals, which determines constrained consumption. Equation (48) is the log-linearized collateral constraint. $v_{t}$ is a demand shock reflecting exogenous changes to demand such as fiscal policy or changes in tastes.

\section{Housing Equations}

$$
\begin{gathered}
\frac{H^{u}}{Y} \widehat{h}_{t}^{u}+\frac{H^{c}}{Y} \widehat{h}_{t}^{c}=0, \\
\widehat{h}_{t}^{u}=\frac{1}{1-\beta}\left(\widehat{c}_{t}^{u}-\widehat{q}_{t}\right)-\frac{\beta}{1-\beta} E_{t}\left(\widehat{c}_{t+1}^{u}-\widehat{q}_{t+1}\right),
\end{gathered}
$$




$$
\widehat{h}_{t}^{c}=\frac{1-k_{S S} \beta}{\Phi} \widehat{c}_{t}^{c}-\frac{1}{\Phi} \widehat{q}_{t}-\frac{k_{S S} \beta}{\Phi}\left[\left(\alpha \widehat{r}_{t}-E_{t} \widehat{\pi}_{t+1}\right)-\widehat{k}_{t}\right]+\frac{\widetilde{\beta}}{\Phi} \widehat{q}_{t+1}-\frac{\widetilde{\beta}\left(1-k_{S S}\right)}{\Phi} E_{t} \widehat{c}_{t+1}^{c}-\frac{\widetilde{\beta} k_{S S}}{\Phi} \widehat{k}_{t} .
$$

Equation (49) is the log-linearized market clearing condition for housing. Equation (50) is the housing margin for unconstrained consumers. Equation (51) is the analogous expression for constrained consumers.

\section{Aggregate Supply}

$$
\begin{gathered}
\widehat{y}_{t}=-\frac{1}{\eta-1}\left(\gamma \widehat{c}_{t}^{u}+(1-\gamma) \widehat{c}_{t}^{c}+\widehat{x}_{t}\right), \\
\widehat{\pi}_{t}=(1-\phi) E_{t} \widehat{\pi}_{t+1}+\phi \widehat{\pi}_{t-1}-\widetilde{k} \widehat{x}_{t}+u_{\pi t} .
\end{gathered}
$$

Equation (52) is the production function combined with labor market clearing. Equation (53) is the New Keynesian Phillips curve with a lagged inflation term, where $\widetilde{k} \equiv(1-\theta)(1-\beta \theta) / \theta$ and $u_{\pi t}$ is a normally distributed cost-push shock.

\section{Monetary Policy}

$$
\widehat{r}_{t}=\rho \widehat{r}_{t-1+}(1-\rho)\left[\left(1+\phi_{\pi}\right) \widehat{\pi}_{t}+\phi_{y}\left(\widehat{y}_{t}-\widehat{y}_{t-1}\right)\right]+e_{t} .
$$

